\title{
Article \\ Performance Comparison of Control Strategies for Plant-Wide Produced Water Treatment
}

\author{
Leif Hansen (D), Mads Valentin Bram $\mathbb{D}^{\mathrm{D}}$, Simon Pedersen $\mathbb{D}^{\mathrm{D}}$ and Zhenyu Yang *(D) \\ Department of Energy, Aalborg University, Niels Bohrs vej 8, 6700 Esbjerg, Denmark; leifh@et.aau.dk (L.H.); \\ mvb@energy.aau.dk (M.V.B.); spe@energy.aau.dk (S.P.) \\ * Correspondence: yang@energy.aau.dk; Tel.: +45-2184-7937
}

Citation: Hansen, L.; Bram, M.V.; Pedersen, S.; Yang, Z. Performance Comparison of Control Strategies for Plant-Wide Produced Water Treatment. Energies 2022, 15, 418. https://doi.org/10.3390/en15020418 Academic Editor: Dino Musmarra

Received: 25 November 2021 Accepted: 22 December 2021 Published: 6 January 2022

Publisher's Note: MDPI stays neutral with regard to jurisdictional claims in published maps and institutional affiliations.

Copyright: (C) 2022 by the authors. Licensee MDPI, Basel, Switzerland. This article is an open access article distributed under the terms and conditions of the Creative Commons Attribution (CC BY) license (https:// creativecommons.org/licenses/by/ $4.0 /)$.

\begin{abstract}
Offshore produced water treatment (PWT) accounts for cleaning the largest waste stream in the offshore oil and gas industry. If this separation process is not properly executed, large amounts of oil are often directly discharged into the ocean. This work extends two grey-box models of a threephase gravity separator and a deoiling hydrocyclone, and combines them into a single plant-wide model for testing PWT control solutions in a typical process configuration. In simulations, three known control solutions-proportional-integral-derivative (PID) control, $\mathrm{H}_{\infty}$ control, and model predictive control (MPC) - are compared on the combined model to evaluate the separation performance. The results of the simulations clearly show what performance metrics each controller excels at, such as valve wear, oil discharge, oil-in-water (OiW) concentration variance, and constraint violations. The work incentivizes future control to be based on operational policy, such as defining boundary constraints and weights on oil discharge, rather than maintaining conventional intermediate performance metrics, such as water level in the separation and pressure drop ratio (PDR) over the hydrocyclone.
\end{abstract}

Keywords: oil and gas; model predictive control; robust control; grey-box modeling; separation; deoiling; hydrocyclone

\section{Introduction}

During the world's transition to renewable energy, it is important to produce the necessary oil and gas with the smallest possible environmental impact. Production of oil is still expected to increase by $0.6 \%$ globally to meet the increasing demands of the next 30 years [1,2]. The Energy Information Administration (EIA) predicts that by 2050, natural gas, crude oil, and other liquids will still account for $48.4 \%$ of all combined energy sources, unless radical changes occur [2]. The extracted liquid mixture from the mature offshore underground reservoir contains approximately $90 \%$ water, which consists of both naturally occurring water and injected sea water. This water is cleaned by PWT facilities before the produced water is discharged to the sea [3]. This remains the largest waste stream from offshore oil and gas production [4,5]. While the discharged water can contain different pollutants, the most severe by quantity is oil content, which is the only pollutant considered for this work. Among the other pollutants are chemicals used either for enhanced oil recovery, to chemically clean the produced water, or as corrosion inhibitors, the effect of these chemicals can be to change the characteristics of the oil and, to a lesser degree, the water. The oil characteristics also vary depending on the underground reservoir, but generally the oil is less dense than water, which enables the used separation technologies.

PWT commonly consists of multiple separation stages of deoiling units, where each individual sub-system affects the others [6]. Thus, it is crucial to consider the overall system behavior in the control strategies, often referred to as plant-wide control [7]. A typical offshore deoiling PWT process [8] is illustrated in Figure 1, where a mixture of 
oil, gas, and water enters multiple stages of three-phase separator tanks. From there, the extracted oil and gas is sent to further processing while the water undertakes additional purification by hydrocyclones to separate suspended oil droplets. After a degassing process, the produced water is discharged to sea and must therefore comply with the governing legislation which for the North Sea is (1) a maximum discharged OiW concentration of 30 PPM [9] and (2) a maximum total annual oil discharge of $222 \mathrm{t}$ for the Danish sector of the North Sea [10]. In 2015, Mærsk Oil discharged 193 t of their allowed total discharge of $202 \mathrm{t}$, which highlights the challenge of cleaning produced water [10]. Despite being cleaned through various processes, the produced water still contains oil, which raises various environmental concerns [11-18]. The increasing demands for more environmental protection have caused the discharge regulations to generally become stricter and the converge to approach zero harmful discharge $[3,12,18]$.

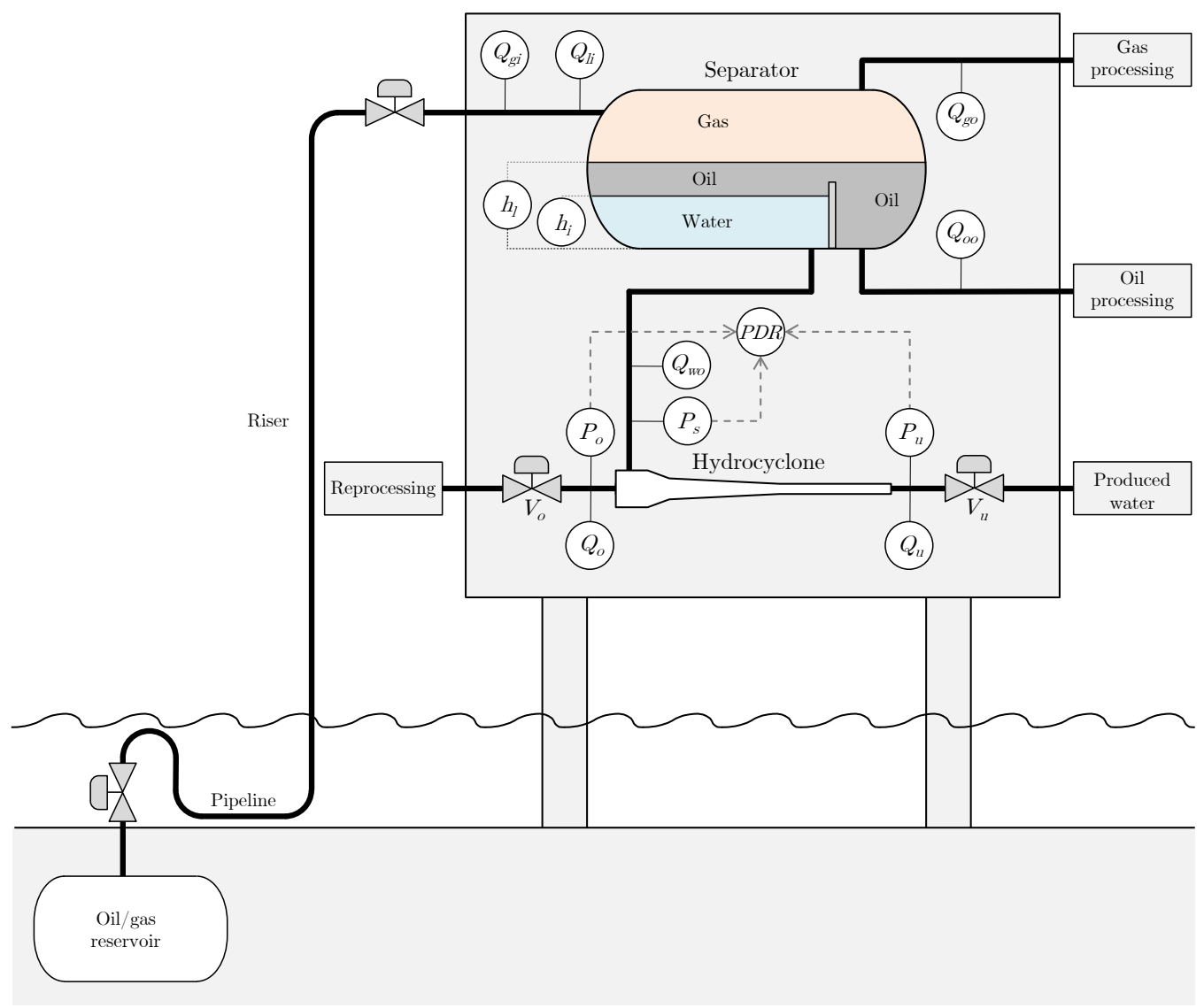

Figure 1. Overview of the offshore oil and gas production and produced water treatment [19].

Conventional control of the PWT system with its associated fundamental challenges is described in [7]. In PWT there are two common separation technologies; three-phase separator tank and hydrocyclone, which are controlled by separate PID controllers designed for each individual separation technology or empirically designed coupling PIDs [20-22]. The fundamental problems related to the commonly deployed PWT control solution are addressed in $[19,21]$ :

- The performance of the hydrocyclone is dependent on $Q_{i}$ and its variations, which is determined from the control of the separator tank;

- $\quad$ Aggressive $h_{i}$ control will propagate $Q_{l i}$ disturbances to $Q_{w 0}$, which affects the performance of the hydrocyclone;

- As $F_{s}$ is strongly related to $V_{u}$, the actions of the $h_{i}$ controller commonly cause the $F_{s}$ controller to saturate $V_{o}$; 
- It is proven that $P D R$ and $F_{S}$ is proportional. However, there exists operational conditions where $F_{S}$ and separation performance is uncorrelated.

Hence, it is clear that the conventional PWT performance is sensitive to fluctuating production rates, such as for the presence of severe slug flow [23-27].

Recent work on exploiting the interdependent system include $\mathrm{H}_{\infty}$ control to operate the valves in a coordinated manner to improve the system's robustness towards fluctuating flow and reduce the oil concentration of the produced water [28], the MPC with similar goals and explicit handling of constraints [29], and model-based optimal operation with an objective of maximizing water removal to improve performance of a sub-sea separation system [30]. For this work, the $\mathrm{H}_{\infty}$ and MPC solutions have been chosen for their focus on lowering the oil discharge and compared with a PID solution in simulations. To simulate the operation of the plant for this work, a model of the separator from [31] and a model of the hydrocyclone from [32] have been extended and combined. It is hypothesized that:

- The PID solution will propagate inflow fluctuations to the hydrocyclone and have the worst deoiling performance.

- The $\mathrm{H}_{\infty}$ and MPC solutions will buffer the inflow fluctuations in the separator and have higher deoiling performance than the PID solution.

- The $\mathrm{H}_{\infty}$ and MPC solutions will only differ when the constraints of the MPC solution are active, at which point it is unknown which solution will have the higher deoiling performance.

The two main contributions of this paper are summarized as (1) introducing a threephase separator model with oil droplet trajectory-based separation in a combined PWT grey-box model and (2) using the combined model for simulating and comparing different deoiling control solutions' performance. The rest of the paper is organized as follows: Section 2.1 describes modeling for the testing facility, Section 2.2 describes the control solution, Section 2.3 describes the emulated and modelled scenarios with associated operation conditions, Sections 3 and 4 presents and discusses the simulation results, and finally a conclusion is presented in Section 5.

\section{Methods}

This section describes the used models and the chosen scenario for the separation performance comparison experiment.

\subsection{Grey-Box Modeling}

The model used in this work is an extension of the combined model proposed in [33]. The separator tank model has been replaced by the separator tank model from [31], which computes trajectories of the suspended oil droplets in the water phase. As a result, both the separator tank model and the hydrocyclone deploy the same technique to estimate separation performance, which is based on evaluation of the droplet trajectories' terminal state. An overview of the expanded model is illustrated in Figure 2.

\subsubsection{Separator Tank}

The separator model used for this work is divided into two parts: a flow part that is a mass balance model for the interface (water) level, the total liquid level, and the gas pressure and a separation part that uses droplet trajectories and initial droplet distributions to calculate separation flows, outlet concentrations, and outlet droplet distributions. 


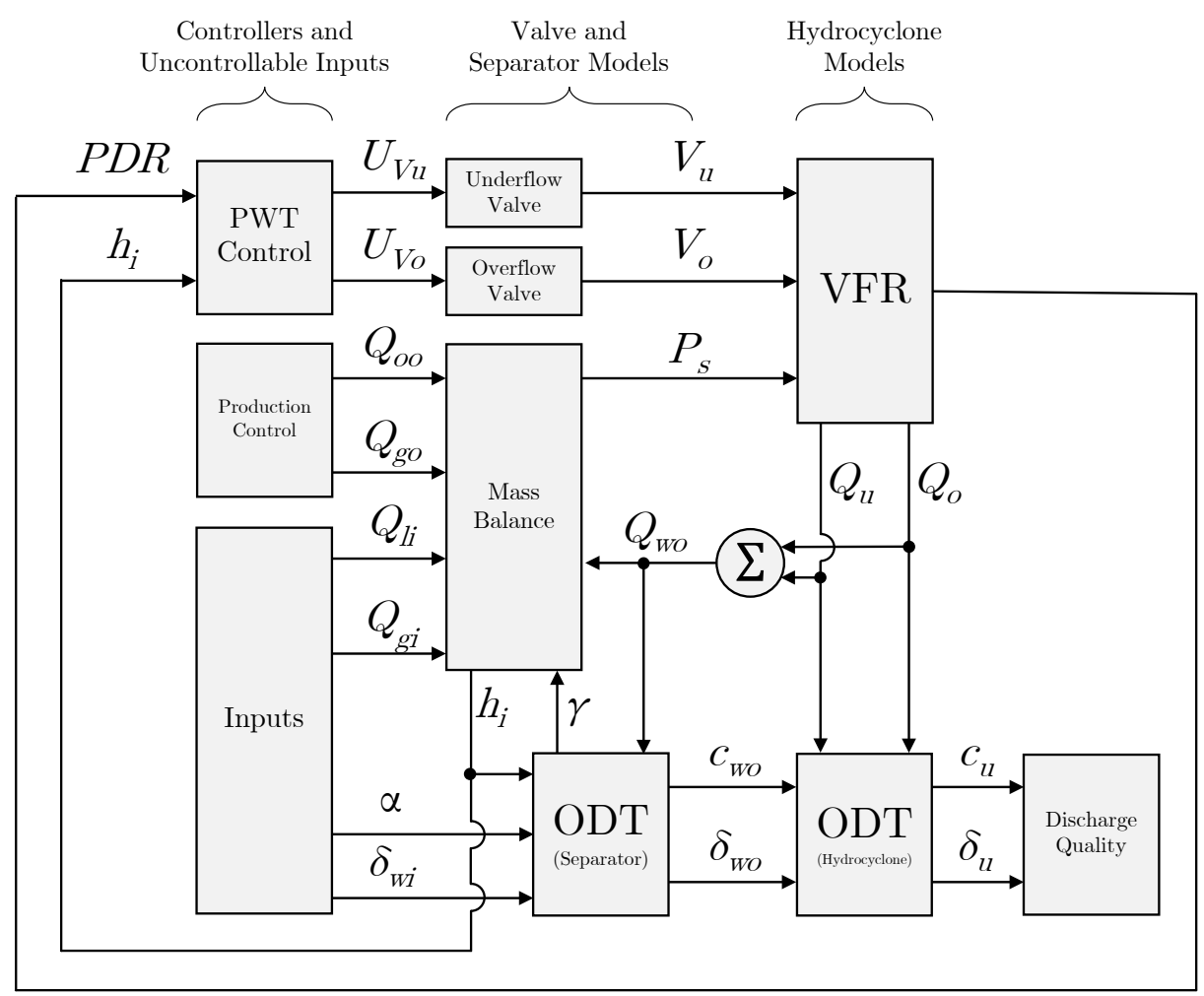

Figure 2. Overview of the combined grey-box model of the separator and hydrocyclone with a control unit that sets valve openings to the underflow and overflow valve and a production control unit that sets oil and gas flow rates.

This model has been updated in the following ways:

- Superficial velocity of water through the separator's water phase is now calculated from the water outlet flow rate. This change reduces the reliance on arbitrary parameters as described in Equation (8).

- The residence time is now calculated for each sample by summing the horizontal distance traveled for each sample going backwards in time starting from the water outlet ending at the input flow region. The residence time is then the total number of samples required to travel that distance multiplied by the sample time. This change more accurately estimates the residence time as described in Equations (9) and (10).

- Initial $\mathrm{WiO}$ and $\mathrm{OiW}$ ratios, $\varphi_{w i o}$ and $\varphi_{o i w}$, are now parameters instead of inputs, as both are assumed constant to simplify the simulation model.

- Initial $\mathrm{WiO}$ ratio parameter $\varphi_{\text {wio }}$ is set to 0 , and there is no longer a need for a water droplet distribution. This work does not concern water in the oil phase and is therefore excluded in the simulation model.

\section{Mass Balance}

The three mass balance states are:

$$
\begin{gathered}
\dot{P}_{S}=\frac{\frac{R T}{M_{G}}\left(Q_{g i}-Q_{g o}\right)+P_{S}\left(Q_{l i}-Q_{w o}-Q_{o o}\right)}{L\left(A(0.6)-A\left(h_{l}\right)\right)}, \\
\dot{h}_{l}=\left(Q_{l i}-Q_{w o}-Q_{o o}\right) \frac{1}{2 L \sqrt{h_{l}\left(2 r-h_{l}\right)}}, \text { and } \\
\dot{h}_{i}=\left(\gamma Q_{l i}-Q_{w o}\right) \frac{1}{2 L \sqrt{h_{i}\left(2 r-h_{i}\right)}},
\end{gathered}
$$


where $T=293^{\circ} \mathrm{K}$ and $L=1 \mathrm{~m}$ is the length of the separation zone, $A(x)$ is a function for the cross-section area below the height $x$ of a circle with radius $0.3 \mathrm{~m}$, and $\gamma$ is:

$$
\gamma=\alpha\left(1-\varphi_{\text {wio }} \zeta_{\text {wio }}\right)+(1-\alpha) \varphi_{\text {oiw }} \zeta_{\text {oiw }},
$$

but as $\varphi_{w o}$ is set to 0 it is reduced to:

$$
\gamma=\alpha+(1-\alpha) \varphi_{o i w} \zeta_{o i w} .
$$

where $\alpha$ is the water-cut of $Q_{l i}$, and $\zeta_{\text {oiw }}$ is the ratio of oil entering the water phase as droplets remaining in the water phase after separation.

\section{Oil Droplet Trajectory}

The residence time of the water phase was calculated assuming steady state as

$$
t_{r}=\frac{L A\left(h_{i}\right)}{Q_{w p}},
$$

where $Q_{w p}$ is the flow in the water phase based on $Q_{l i}$;

$$
Q_{w p}=Q_{l i}\left(\alpha\left(1-\varphi_{w i o}\right)+(1-\alpha) \varphi_{\text {oiw }}\right) .
$$

To reduce reliance on the rather arbitrary parameters $\varphi_{w i o}$ and $\varphi_{o i w}$, the updated model use $Q_{w o}$ instead of $Q_{w p}$. The superficial velocity through the water phase is:

$$
v_{s}=\frac{Q_{w o}}{A\left(h_{i}\right)},
$$

but as $Q_{w o}$ is dominated by $V_{u}$, which is set by the control solutions, and combined with the steady-state assumption, this gives the control solutions much more power over the residence time. Therefore the superficial velocity is stored in a vector each sample, where the first element is the superficial velocity for this sample and the $n^{\text {th }}$ element is the superficial velocity $n-1$ samples ago. The residence time in number of samples, $N_{r t}$, is found by solving:

$$
\sum_{i=1}^{N} s_{t} v_{S}[i] \geq L,
$$

for $N$, where $s_{t}$ is the sample time, and setting $N_{r t}$ to the lowest value in the solution set for $N$. The residence time of the water phase is calculated as:

$$
t_{r}=N_{t r} s_{t} .
$$

The remaining equations in this section are equivalent to equations from [31]. The distance traveled vertically by each droplet size in $d$ is:

$$
h_{o d}[i]=t_{r} \frac{g d[i]^{2} \Delta \rho}{18 \mu},
$$

where $\mu$ is the dynamic viscosity of water and $\Delta \rho$ is the density difference between water and oil. The ratio of droplets of each size there remain in the water phase is:

$$
r_{w o}[i]=\left\{\begin{array}{ll}
A\left(h_{i}-h_{o d}[i]\right) / A\left(h_{i}\right) & h_{i}-h_{o d}[i]>0 \\
0 & h_{i}-h_{o d}[i] \leq 0
\end{array} .\right.
$$


The reduced distribution of the oil droplets in water outlet is:

$$
\delta_{w o}=r_{w o} \circ \delta_{w i},
$$

where $\circ$ is the Hadamard (element-wise) product. $\zeta_{\text {oiw }}$ is:

$$
\zeta_{o i w}=\sum \delta_{w o},
$$

and $c_{w o}$ is:

$$
c_{w o}=\frac{(1-\alpha) \varphi_{o i w} \zeta_{o i w}}{\gamma} .
$$

\subsubsection{Hydrocyclone}

This section will describe the grey-box model of the hydrocyclone to be used, which is divided into two parts: virtual flow resistance (VFR) and oil droplet trajectory.

Virtual Flow Resistance

In the VFR model, the flows are solved based on a set of five pressure-drop equations. Three of the equations are from virtual hydrocyclone orifice equations with the structure

$$
\Delta P=\frac{Q^{2}}{K},
$$

and the pressure drop over the hydrocyclone valves are assumed as

$$
\Delta P_{V u}=\frac{Q_{u}^{2}}{\left(K_{V u} V_{u}\right)^{2}}
$$

and

$$
\Delta P_{V u}=\left(\frac{Q_{o}}{K_{V o 1} V_{o}^{\frac{1}{2}}}\right)^{2}+\frac{Q_{o}^{2}}{K_{V o 2}^{2}},
$$

which have been chosen in [32] to emulate the properties of the used pilot plant. This set of equations is solved for $Q_{u}$ and $Q_{o}$ using the known inputs $P_{s}, V_{u}$, and $V_{o}$. This VFR model was first proposed and validated in [34].

\section{Oil Droplet Trajectory}

The second part of the hydrocyclone model estimates the oil droplets' spacial trajectories by setting up simple velocity fields that are dependent on $Q_{u}$ and $Q_{o}$. This enables the oil droplet trajectory (ODT) model to provide statistical estimations on the expected $c_{u}$ and $\delta_{u}$, given known $c_{w o}$, and $\delta_{w o}$ by

$$
\delta_{u}=r_{u} \circ \delta_{w o},
$$

and

$$
c_{u}=\frac{Q_{w o} c_{w o} \sum \delta_{u}}{Q_{u} \sum \delta_{w o}},
$$

where, $r_{u}$ is from

$$
r_{u}[i]=\frac{2 \pi \int_{\frac{R_{d}(d[i])}{R_{z}(0)}}^{1} r Y(r) d r}{Q_{w o}},
$$

where $R_{z}(0)=10 \mathrm{~mm}$ for the hydrocyclone used, $R_{d}(d)$ is the starting radial position of all the critical droplet trajectories, and $Y(r)=\theta_{1}+\theta_{2} r+\theta_{3} r^{2}+\theta_{4} r^{3}$ is the axial velocity profile. The axial velocity is solved based on volume balance of incompressible flow:

1. Maximum axial velocity at the inner wall where $(r, z)=\left(R_{z}(0), 0\right)$ :

$$
\left.\frac{d Y(r)}{d r}\right|_{r=R_{z}(0)}=0
$$


2. Minimum axial velocity at the center axis, where $(r, z)=(0,0)$ :

$$
\left.\frac{d Y(r)}{d r}\right|_{r=0}=0
$$

3. Volume balance of the forward flow, where $z=0$ :

$$
\left(1+R_{R}\right)\left(Q_{u}+Q_{o}\right)=2 \pi \int_{R_{L}}^{1} Y(r) r d r
$$

4. Volume balance of the reverse flow, where $z=0$ :

$$
\left(1+R_{R}\right) Q_{o}+R_{R} Q_{u}=-2 \pi \int_{0}^{R_{L}} Y(r) r d r,
$$

For the constraints, $R_{R}=2 \%$ is the recirculation rate, and $R_{L}$ defined by

$$
Y\left(R_{L}\right)=0
$$

The critical droplet trajectories are from the axial velocity field

$$
W_{c}(r, z)=\left(1-\frac{\left|\frac{\left(1+R_{R}\right) Q_{o}+R_{R} Q_{u}}{\pi \frac{R_{L}(z)}{R_{z}(z)}\left(L_{3}\left(\frac{D_{n}+D_{u}}{2}\right)+L_{4} D_{u}\right)} 2 \pi \int_{0}^{z} R_{L}(z) d z\right|}{\left(1+R_{R}\right)\left(Q_{u}+Q_{o}\right)} \mid Y(r),\right.
$$

and the radial velocity field

$$
U_{d}(r, z)[i]=\frac{-r}{R_{z}(z)} W_{c}(r, z) \tan \left(\frac{\beta_{2}}{2}\right)-\frac{\Delta \rho d[i]^{2} T(r, z)^{2}}{18 \mu r},
$$

where

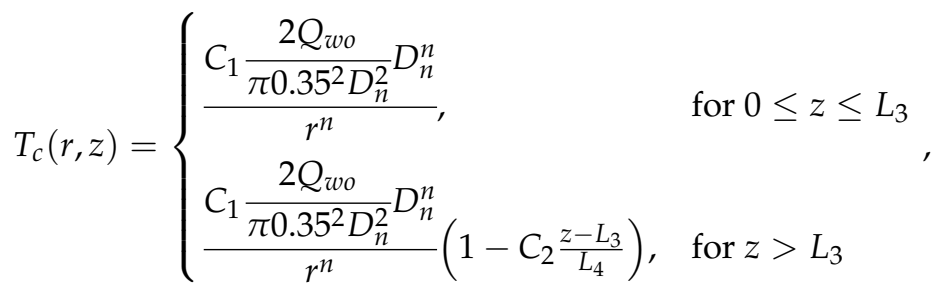

where $L_{3}=38.2 \mathrm{~cm}, L_{4}=60 \mathrm{~cm}, D_{n}=2 \mathrm{~cm}, D_{u}=1 \mathrm{~cm}, R_{z}(z)$ is the inner hydrocyclone wall radius along the axial length, $C_{1}$ is an imperfection coefficient between inlet velocity and rotating velocity [35], $C_{2}$ is a loss coefficient that slows the rotating velocity along the cylindrical segment of the hydrocyclone, and $(r, z)$ are positions in the radial-axialcoordinate system. With $W(r, z)$ and $U_{d}(r, z)[i]$, the critical oil droplet trajectory that intersects with the boundary between the flow being separated and the flow not being separated is calculated numerically for each element in $d$ or until $d=d_{100}$. This ODT model was proposed in [36], extended in [37], and later validated in [19,32].

\subsection{Control Candidates}

This section describes the three deployed control solutions: PID as a conventional benchmark control strategy, and the two control candidates chosen in this work: $\mathrm{H}_{\infty}$ control and MPC. The control solutions have two measured variables, $h_{i}$ and PDR, and manipulate the requested opening degree to two control valves: $U_{V u}$ and $U_{V o}$. These measured and manipulated variables are chosen to represent the control challenges associated with controlling both the separator tank and the hydrocyclone simultaneously. As all three control solutions are based on linear design methods, all values in this section are relative to the equilibrium points of the linear model form [28]. 


\subsubsection{PID Control}

This control solution represents the commonly deployed control solution, where one PID controller uses $h_{i}$ as feedback and manipulates $V_{u}$ and the other PID controller uses PDR as feedback and manipulates $V_{0}$. The PID controllers used in this work were first implemented in [28], but the lower saturation limit of $U_{V o}$ is changed from 0 to $3 \%$, which is to have identical valve saturation values for all compared controllers. The transfer functions for the two PID controllers are experimentally found in [28] and are

$$
\frac{U_{V u}(s)}{E_{h i}(s)}=-58.37-\frac{1.067}{s}, \text { and } \frac{U_{V o}(s)}{E_{P D R}(s)}=0.1+\frac{0.1}{s},
$$

where the design goal is to emulate the performance characteristics of a PID controlled offshore PWT system on the linear model.

\subsection{2. $\mathrm{H}_{\infty}$ Control}

The $\mathrm{H}_{\infty}$ controller was first implemented to PWT in [28]. The intention of using this controller is to relax $h_{i}$ control, as maintaining a specific $h_{i}$ is not important. It is only necessary to keep $h_{i}$ within certain bounds. This leads to more stable PDR and $Q_{w o}$, which are important for the hydrocyclone's performance.

This solution is based on the lower linear fractional transformation as seen in Figure 3, which is commonly used in $\mathrm{H}_{\infty}$ control design, where $P_{H}$ is a linear model of the system including set-point and disturbance inputs and $K_{H}$ is the control solution. The four signal vectors in the design are:

$$
w_{H}=\left[\begin{array}{c}
r_{h i} \\
r_{P D R} \\
d_{H}
\end{array}\right], u_{H}=\left[\begin{array}{l}
U_{V u} \\
U_{V o}
\end{array}\right], z_{H}=\left[\begin{array}{c}
h_{i} \\
P D R
\end{array}\right] \text {, and } y_{H}=\left[\begin{array}{c}
E_{h i} \\
E_{P D R}
\end{array}\right],
$$

where $r_{h i}$ and $r_{P D R}$ are the set-points for $h_{i}$ and $P D R$, respectively, and $d_{H}$ is the disturbance caused by inflow to the separator's water phase. The linear model of PWT system has the state space form:

$$
\begin{aligned}
& \dot{x}_{H}=A_{l} x_{H}+B_{l} u_{H}+B_{d} d_{H} \\
& z_{H}=C_{l} X_{H},
\end{aligned}
$$

where the disturbance input matrix $B_{d}$ models the disturbance as valve errors. The augmented model $P_{H}$ becomes:

$$
\begin{aligned}
& \dot{x}_{H}=A_{l} x_{H}+\left[\begin{array}{ll}
0_{52} & B_{d}
\end{array}\right] w_{H}+B_{l} u_{H} \\
& z_{H}=C_{l} X_{H}+0_{24} w_{H}+0_{22} u_{H} \\
& y_{H}=-C_{l} X_{H}+\left[\begin{array}{ll}
I_{22} & 0_{22}
\end{array}\right] w_{H}+0_{22} u_{H},
\end{aligned}
$$

The designed controller, $K_{H}$, is a dynamic system of the same order as $P_{H}$ with $y_{h}$ as input and $u_{H}$ as output. This solution is a $\mathrm{H}_{\infty}$-optimal solution; i.e., it minimizes the $\mathrm{H}_{\infty}$-norm of the closed loop in Figure 3.

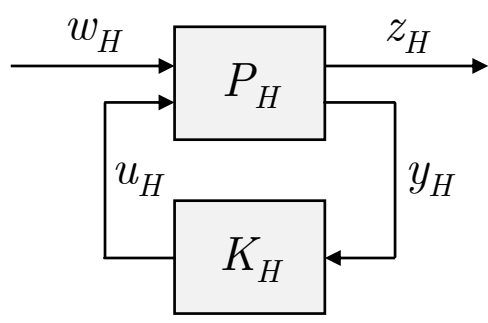

Figure 3. Lower linear fractional transformation diagram for the $\mathrm{H}_{\infty}$ solution. 
The designed control solution achieves a $\mathrm{H}_{\infty}$-norm of the closed-loop of 1.0059; for the full overview of the $\mathrm{H}_{\infty}$ solution, see [28].

\subsubsection{MPC}

Similarly to the $\mathrm{H}_{\infty}$, the idea behind the MPC solution is to relax $h_{i}$ control to achieve a more stable PDR. Unlike $\mathrm{H}_{\infty}$ control, MPC enables the definition of upper and lower constraints to explicitly define the upper and lower limits of $h_{i}$. The MPC for this work is based on the Hammerstein MPC proposed in [29], which is designed with the model from [28], but with the disturbance caused by inflow to the separator's water phase as a flow input, $Q_{i d}$, and the model expanded by a Hammerstein function on the input for $U_{V o}$ and an output for the changing rate of the PDR.

To mimic the performance of the Kalman filter after correction of an implementation error, the following changes have been made to the augmented models:

- Input disturbance model updated to the transfer function: $\frac{0.01}{s}$.

- Measurement noise model for $h_{i}$ has been updated to an assumed standard deviation of 0.51 .

- Measurement noise model for PDR has been updated to an assumed standard deviation of 59.1.

The most important input and output vectors of the model as used for MPC design are:

$$
u_{u m}=\left[Q_{i d}\right], u_{r}=\left[\begin{array}{c}
U_{V u} \\
F_{h}\left(U_{V o}\right)
\end{array}\right], \text { and } y_{r}=\left[\begin{array}{c}
h_{i} \\
P D R \\
\frac{\mathrm{d} P D R}{\mathrm{~d} t}
\end{array}\right] \text {, }
$$

where $u_{u m}$ is the unmeasured disturbance input, $u_{r}$ are the controllable inputs, $y_{r}$ are the predicted outputs, and $F_{h}(\cdot)$ is the used Hammerstein function. The objective of the MPC solution is to:

$$
\begin{array}{cl}
\underset{u_{\Delta}}{\operatorname{minimize}} & J\left(u_{\Delta}[0], . ., u_{\Delta}[n], u_{r}[-1], \hat{x}_{o}[0]\right) \\
\text { subject to } & c_{\text {min }} \leq y_{r} \leq c_{\max } \\
& d_{\text {min }} \leq u_{r} \leq d_{\max }
\end{array}
$$

where $\hat{x}_{o}[0]$ is the Kalman filter estimate of the augmented state vector, which include the effect of $u_{u m}, u_{r}[-1]$ is the previous control input, $u_{\Delta}$ is the incremental inputs during the control horizon, and the cost function $J(\cdot)$ can be written as

$$
\begin{aligned}
& J\left(u_{\Delta}[0], . ., u_{\Delta}[n], u_{r}[-1], \hat{x}_{o}[0]\right)= \\
& {\left[\begin{array}{c}
u_{\Delta}[0] \\
\ldots \\
u_{\Delta}[n]
\end{array}\right]^{T}\left[\begin{array}{ccc}
W & & 0 \\
& \ddots & \\
0 & & W
\end{array}\right]\left[\begin{array}{c}
u_{\Delta}[0] \\
\ldots \\
u_{\Delta}[n]
\end{array}\right]+} \\
& {\left[\begin{array}{c}
y_{r}[0] \\
\cdots \\
y_{r}[p]
\end{array}\right]^{T}\left[\begin{array}{llll}
V & & & 0 \\
& \ddots & & \\
& & V & \\
0 & & & V_{T}
\end{array}\right]\left[\begin{array}{c}
y_{r}[0] \\
\cdots \\
y_{r}[p]
\end{array}\right] .}
\end{aligned}
$$


where $W$ is the control weight, $V$ is the tracking error weight, $V_{T}$ is the terminal tracking error weight, and the sequence of $y_{r}$ is calculated from a discrete version of the prediction model. The weights are experimentally selected as:

$$
\begin{aligned}
& W=\left[\begin{array}{cc}
4.5 & 0 \\
0 & 0
\end{array}\right], \\
& V=\left[\begin{array}{ccc}
10^{-2} & 0 & 0 \\
0 & 1.5 & 0 \\
0 & 0 & 5
\end{array}\right] \text {, and } \quad V_{T}=\left[\begin{array}{ccc}
10 & 0 & 0 \\
0 & 1.5 & 0 \\
0 & 0 & 5
\end{array}\right] \text {. }
\end{aligned}
$$

The design goals of the MPC solution, i.e., to relax $h_{i}$ control and achieve a more stable PDR, are expressed in the weights as the high value of $W_{11}$ and low value of $V_{11}$ will relax the $h_{i}$ control, while the high values of $V_{22}$ and $V_{33}$ will keep the focus on PDR control until the higher value of $V_{T 11}$ is reached at the end of the prediction horizon. To give sufficiently large safety margins the constraints of the interface level is selected as: $0.1 \mathrm{~m} \leq h_{i} \leq 0.2 \mathrm{~m}$, which gives:

$$
c_{\min }=\left[\begin{array}{c}
0.1 \\
-\infty \\
-\infty
\end{array}\right], \quad c_{\max }=\left[\begin{array}{c}
0.2 \\
\infty \\
\infty
\end{array}\right] .
$$

The constraint of the underflow valve is $0.1 \leq U_{V u} \leq 1$, and the constraint of the overflow valve is $0.03 \leq U_{V o} \leq 1$. These chosen values are a trade-off between available control agency and safeguard against unintentional shutdown of the hydrocyclone. Applying $F_{h}(\cdot)$ gives $0.038 \leq F_{h}\left(U_{V o}\right) \leq 0.3$, and the input constraints are therefore:

$$
d_{\min }=\left[\begin{array}{c}
0.1 \\
0.038
\end{array}\right], \quad d_{\max }=\left[\begin{array}{c}
1 \\
0.3
\end{array}\right] .
$$

For the full overview of the MPC solution, see [29].

\subsection{Simulation Scenario}

This section describes the process conditions used to compare the three different control solutions. For all simulations, the production controllers are the two PID controllers used in [31] to control the total liquid height $h_{l}$ and the separator gas pressure $P_{s}$. The flow rate entering the three-phase separator is $0.5 \mathrm{~L} / \mathrm{s}$, with added disturbance as shown in Figure 4 .

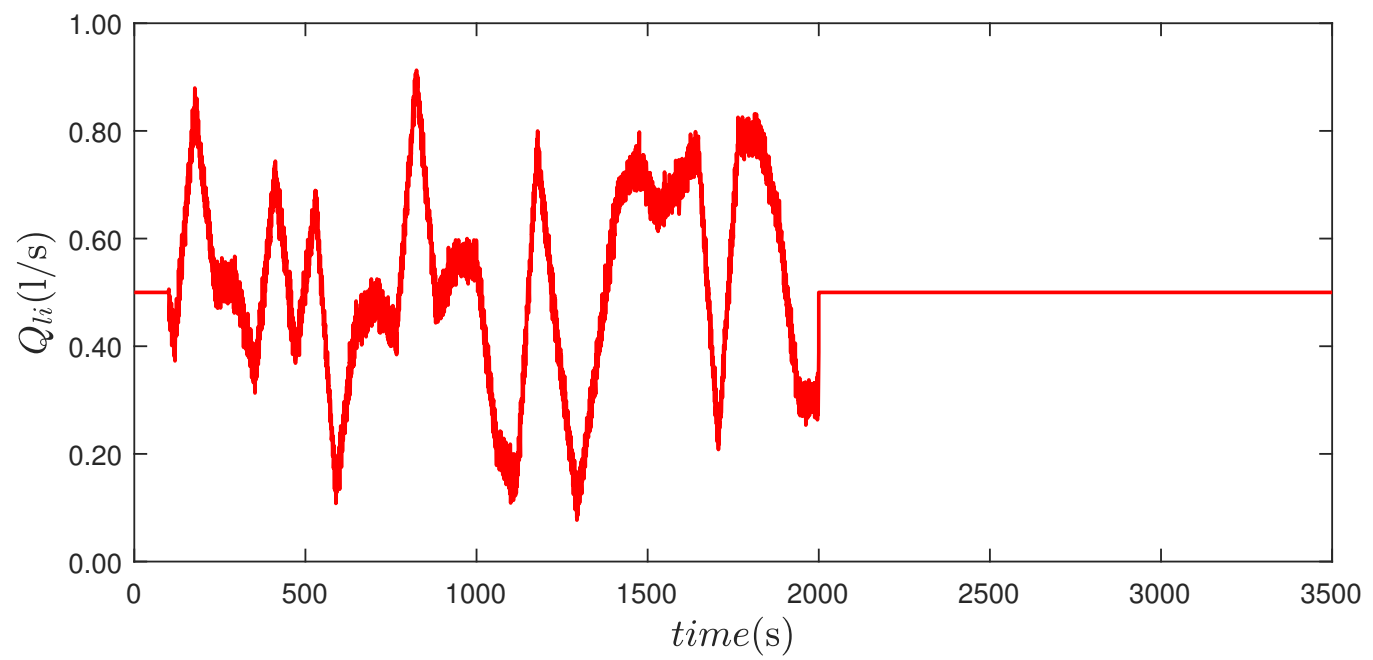

Figure 4. Separator liquid inflow, with the input disturbance from $100 \mathrm{~s}$ to $2000 \mathrm{~s}$, and a steady-state period from $2000 \mathrm{~s}$ to $3500 \mathrm{~s}$. 
The $Q_{\text {in }}$ signal is based on the one described in [29], which is a measured signal during an experiment performed on the scaled-down offshore pilot plant, which is further described in [19]. The $Q_{i n}$ signal has been altered in three ways: (1) a steady-state period of $1500 \mathrm{~s}$ is added to the end of the signal to let the control solutions reach similar end conditions, (2) as the experiment in [29] did not include oil, the signal is divided by the water-cut $(\alpha)$ to keep the water flow the same, and (3) a low pass filter has been applied to the signal to reduce the effect of measurement noise.

The oil droplet diameter vector is: $d=\left[\begin{array}{llllll}1 & 2 & 3 & \cdots & 349 & 350\end{array}\right] \mu \mathrm{m}$, as droplets above $350 \mu \mathrm{m}$ are always separated in the separator under all simulated conditions.

The water-cut $\alpha$ is set to 0.8 as this is the water-cut approached by mature fields in the Danish North Sea in 2017 [38]. As 20\% of the oil that enters the separator is assumed to enter the start of the water phase, the initial OiW ratio parameter $\varphi_{\text {oiw }}$ is set to 0.2 ; combined with $\alpha$, this results in $4 \%$ of the inlet flow arriving at the start of the water phase as oil droplets. The count distribution $\Phi_{i n}$ of these oil droplets is kept constant and is a log-normal distribution with $E\left[\Phi_{i n}\right]=2 \mu \mathrm{m}$ and $S D\left[\Phi_{i n}\right]=7.75 \mu \mathrm{m}$. The oil volume distribution vector $\delta_{w i}$ is:

$$
\delta_{w i}=\frac{\delta_{\log } \circ \psi}{\delta_{\log } \cdot \psi},
$$

where $\cdot$ is the dot product, $\delta_{\log }$ represents the values of an approximated probability mass function of $\Phi_{i n}$ evaluated at the sizes in $d$, and $\psi$ represents the volumes of the droplet sizes in $d$.

Other process conditions during the test are as follows:

- The set-point for the separator gas pressure is $7 \mathrm{bar}$, as this was the operation condition during system identification of the linear model used for the design of both the $\mathrm{H}_{\infty}$ and MPC solutions.

- The set-point for liquid interface height is $0.15 \mathrm{~m}$, and the set-point for the PDR is 2, as these are the equilibrium points of the linear model.

- The weir height is $0.3 \mathrm{~m}$, and the set-point for total liquid height $h_{l}$ is $0.4 \mathrm{~m}$, as these values keep $h_{l}$ above and $h_{i}$ below the weir at all times in the simulations, which is necessary due to model limitations.

The simulation is executed once for each of the three control solutions: PID-control, $\mathrm{H}_{\infty}$, and MPC.

\section{Results}

This section illustrates and summarizes the performances of the three simulated control solutions. For illustrative purposes, the process variables of these three control solutions are shown concurrently, even though they are separate simulations. In all figures in this section, red, green, and blue represent process variables from the PID control, $\mathrm{H}_{\infty}$ control, and MPC solution, respectively.

All three control solutions satisfy $0 \mathrm{~m} \leq h_{i} \leq 0.3 \mathrm{~m}$ which prevents free oil from entering the water outlet and prevents water from overflowing the weir. However, $h_{i}$ of $\mathrm{H}_{\infty}$ is outside $0.1 \mathrm{~m} \leq h_{i} \leq 0.1 \mathrm{~m}$ at $t \approx 1600 \mathrm{~s}$ and $t \approx 1900 \mathrm{~s}$, as seen in Figure 5, where the dashed line represents the weir height and the dotted lines represents the constraints of the MPC controller. It is apparent that the MPC controller satisfies its constraints at all times, and the PID controller maintains $h_{i}$ at $0.15 \mathrm{~m}$ with only small deviations.

All three control solutions satisfy $0.3 \mathrm{~m} \leq H_{l} \leq 0.4 \mathrm{~m}$, which prevents the $H_{l}$ from being lower than the weir height, as seen in Figure 6.

An important process variable for the hydrocyclone performance is the flow rate leaving the water outlet of the separator, which is identical to the flow rate entering the hydrocyclone $Q_{w o}$ and shown in Figure 7. 


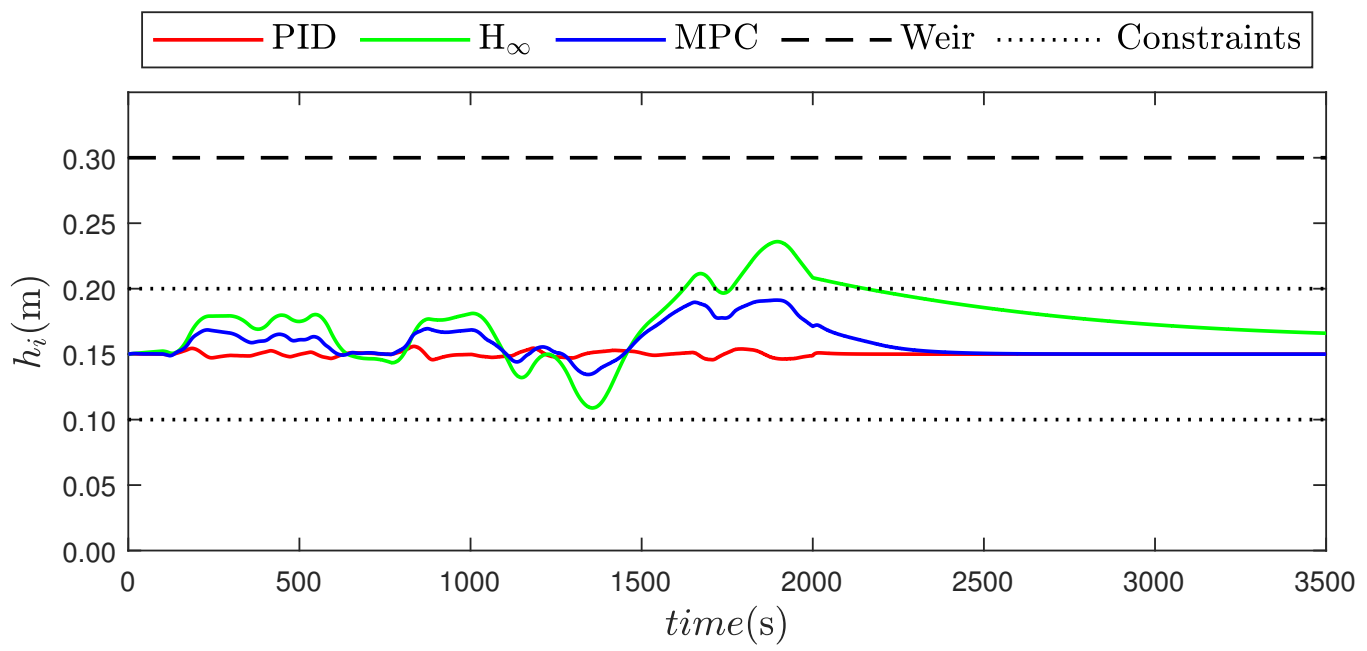

Figure 5. Separator interface level.

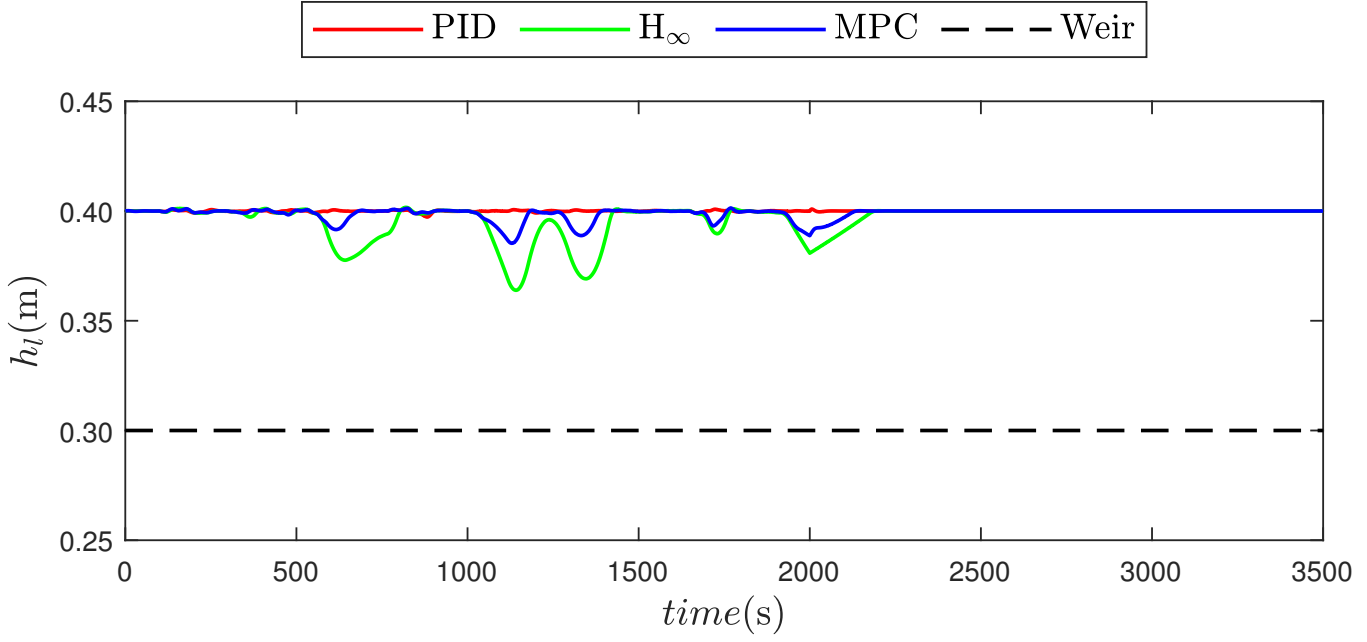

Figure 6. Separator total liquid level.

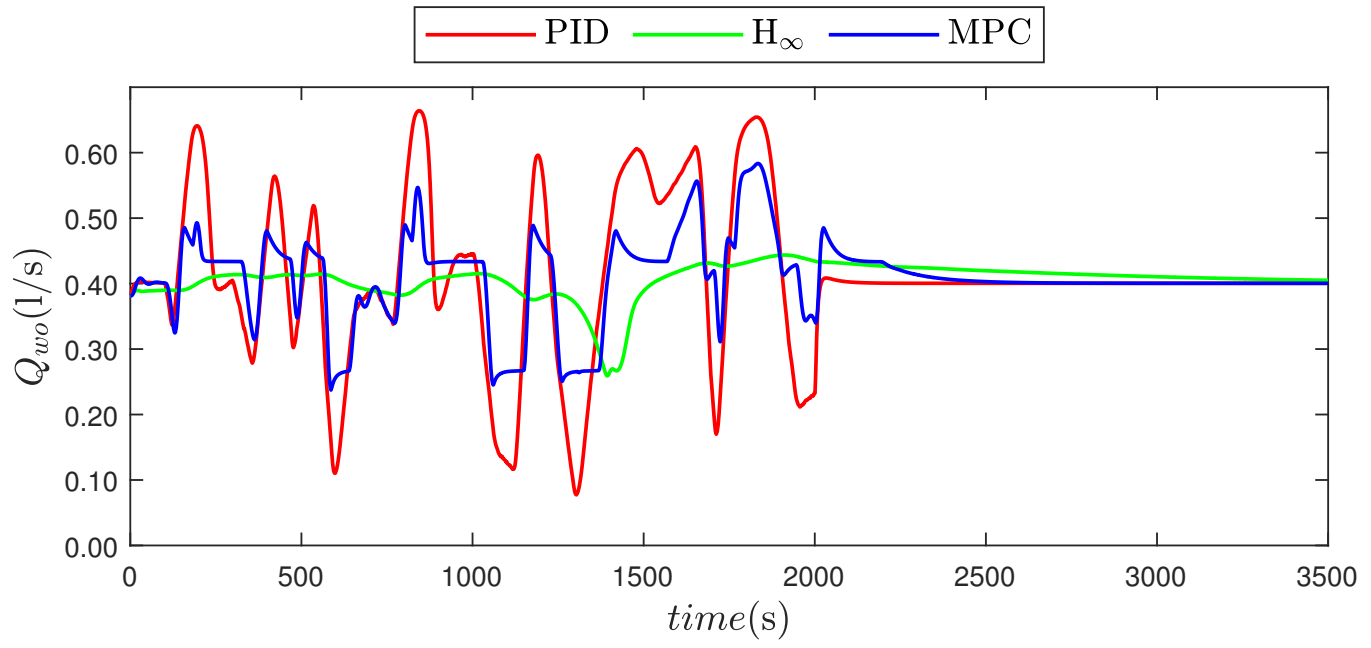

Figure 7. Separator water-phase outlet (hydrocyclone inlet) liquid flow.

If this flow rate is too high, there is evidence that it can reduce separation performance $[33,39,40]$, and the lower this flow rate gets, the weaker the acceleration field strength of the hydrocyclone becomes, which also reduces separation performance. The $\mathrm{H}_{\infty}$ solution has the smallest variations, and the PID solution has the highest variations. For the 
separator, a high flow rate will reduce the residence time and therefore reduce the separation performance, while a low flow rate will increase it. The separator residence time is around $140 \mathrm{~s}$ during the simulations, with variations as seen in Figure 8.

The commanded opening degree of the two control valves at the hydrocyclone outlets $U_{V u}$ and $U_{V o}$ is shown in Figures 9 and 10, respectively. It is evident that the PID solutions actuate $V_{u}$ more aggressively than the $\mathrm{H}_{\infty}$ and MPC solutions. As a result of compensating for the corresponding aggressive changes to PDR, the PID solution also has the highest actuation of $V_{o}$. The $\mathrm{H}_{\infty}$ solution has the most relaxed valve actuation, prioritizing PDR at all times. The MPC solution prioritizes PDR most of the time, by keeping $V_{u}$ in an interval where the PDR can be kept, but does shift its priority to the interface level if it reaches a constraint within the prediction horizon.

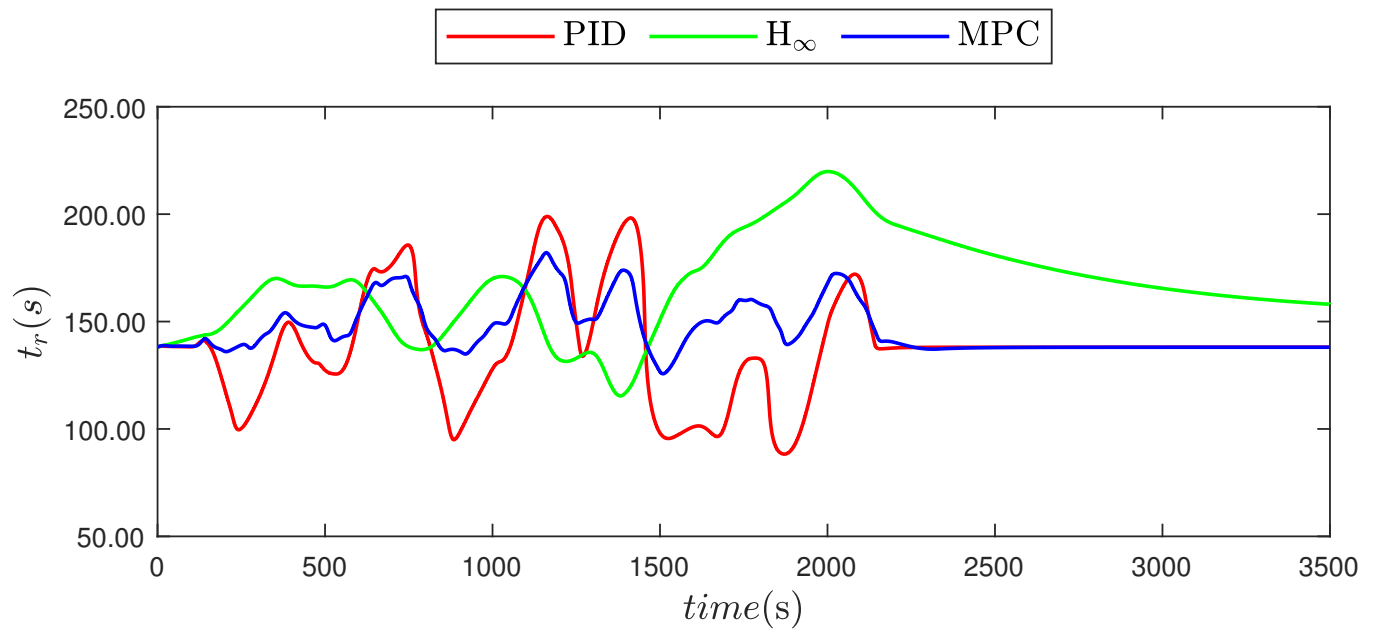

Figure 8. Separator residence time.

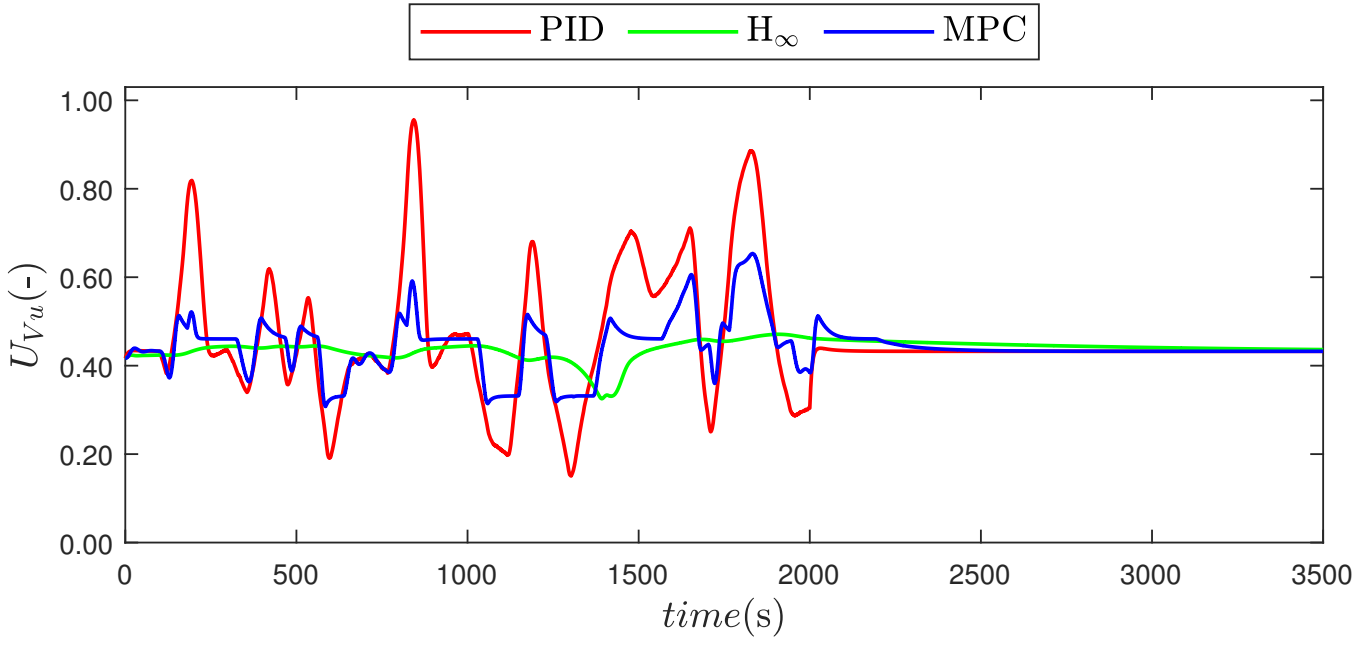

Figure 9. Underflow valve opening.

The PDR during the simulation is shown in Figure 11. As a result of the aggressive changes to $U_{V u}$, the PID solution has large spikes in PDR, while the MPC solution has smaller spikes corresponding to peak values in $Q_{s}$. The $\mathrm{H}_{\infty}$ solution has only small variations in the PDR, corresponding more to $h_{i}$ than $Q_{s}$.

To evaluate the PWT equipment's performance and concentration reduction, the $\mathrm{OiW}$ concentration of the mixture exiting the separator and entering the hydrocyclone $c_{s}$ is shown in Figure 12, the flow rates leaving the hydrocyclone $Q_{u}$ and $Q_{o}$ are shown in Figures 13 and 14, and the OiW concentration of the mixture leaving the hydrocyclone $c_{u}$ is shown in Figure 15. The PID controller has the largest spikes in OiW concentration with 
the largest spike reaching about 45 PPM. These figures also clearly show that low $Q_{u} / Q_{w o}$ gives low $c_{s}$ but high $c_{u}$, and vice versa.

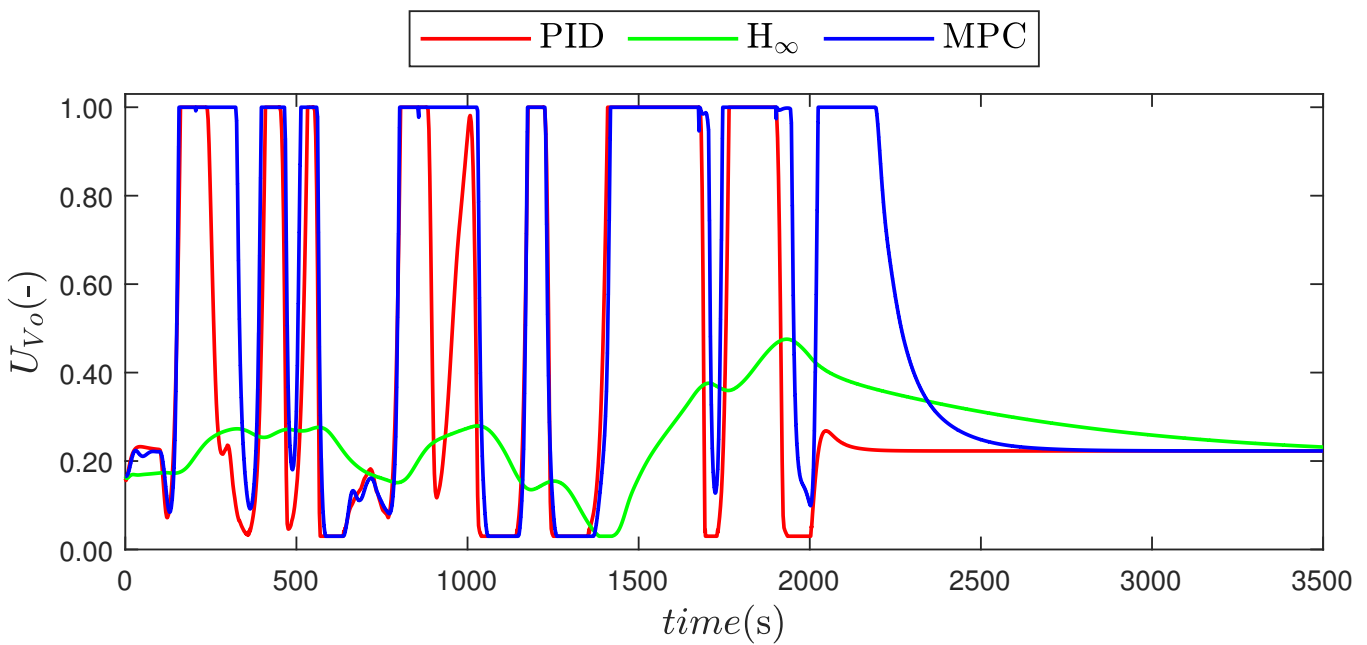

Figure 10. Overflow valve opening.

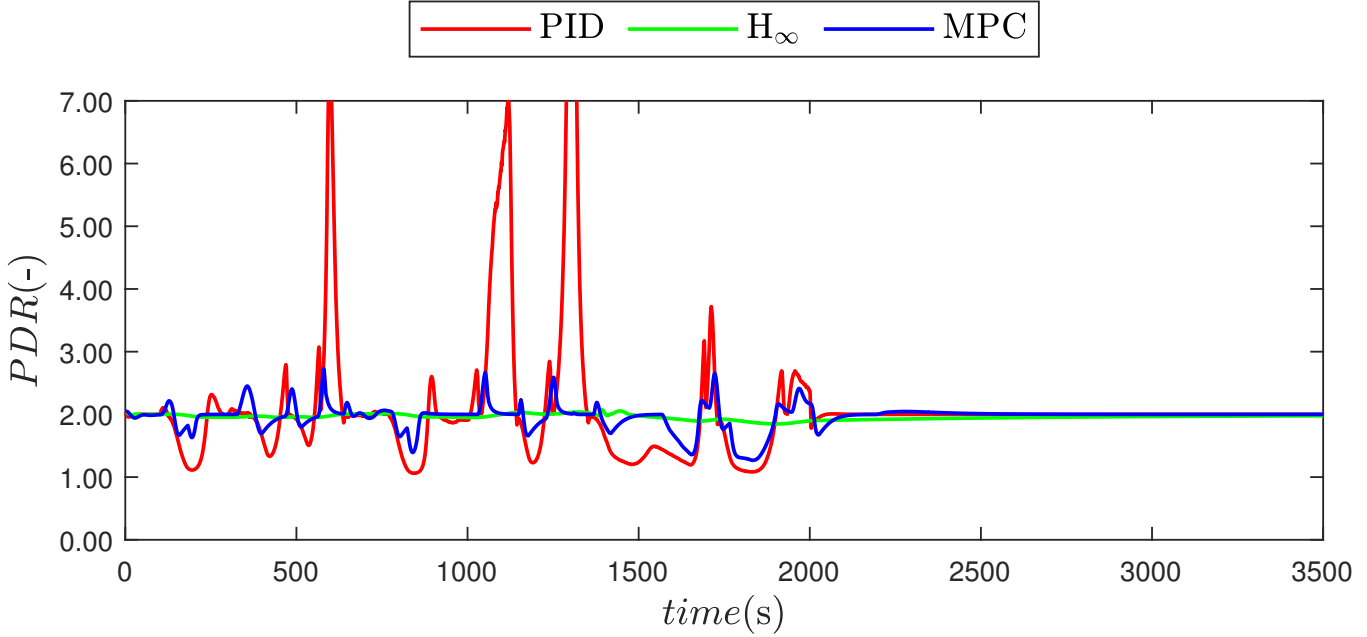

Figure 11. Pressure drop ration (PDR).

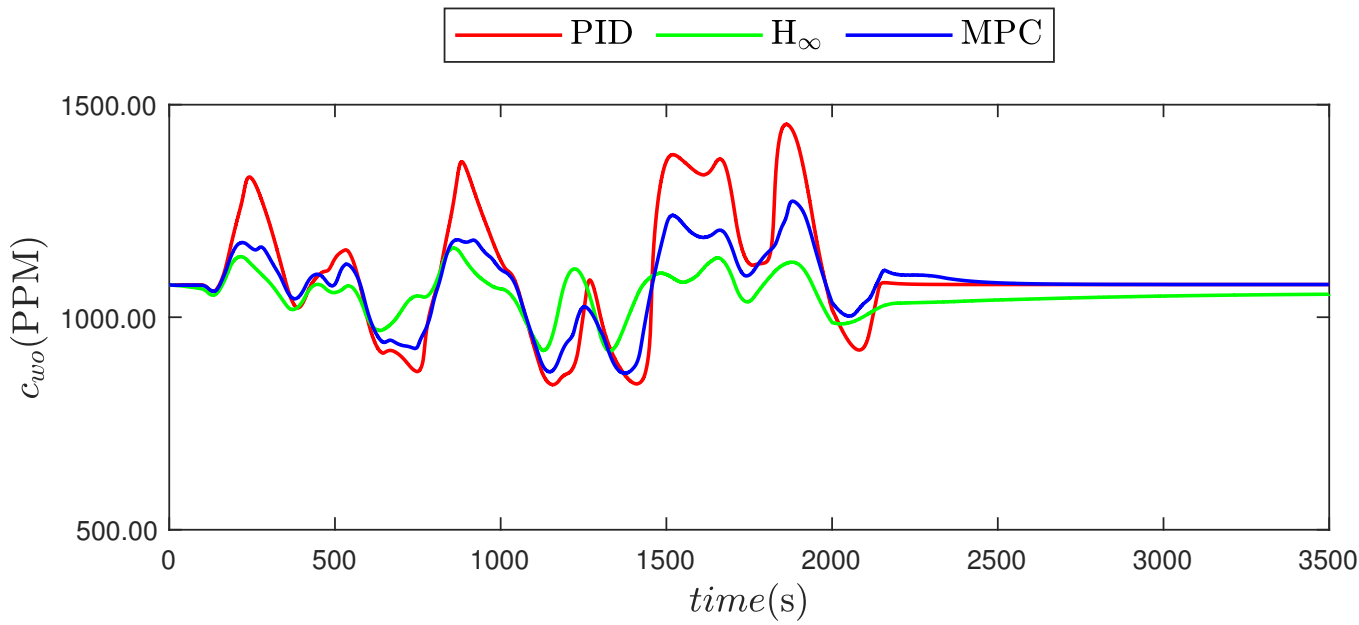

Figure 12. Separator water-phase outlet (hydrocyclone inlet) concentration. 
Figure 16 shows a histogram of the time samples' $c_{u}$. No time sample has a concentration less than 5 PPM. The $\mathrm{H}_{\infty}$ controller has the narrowest spread of concentrations, while the PID control has the widest spread of concentrations, up to 45 PPM, which is seen in Figure 17.

The flow rate of oil leaving the hydrocyclone underflow $Q_{u, o i l}$ is shown in Figure 18. Noteworthy is the PID controller's three downward spikes, where the oil flow rate is lower. These three spikes are concurrent with the upwards spikes in $c_{\mathcal{u}}$ in Figure 15. This is a result of low hydrocyclone throughput, as even though the OiW concentration is high, the oil flow rate is low due to the mixture flow rate being low.

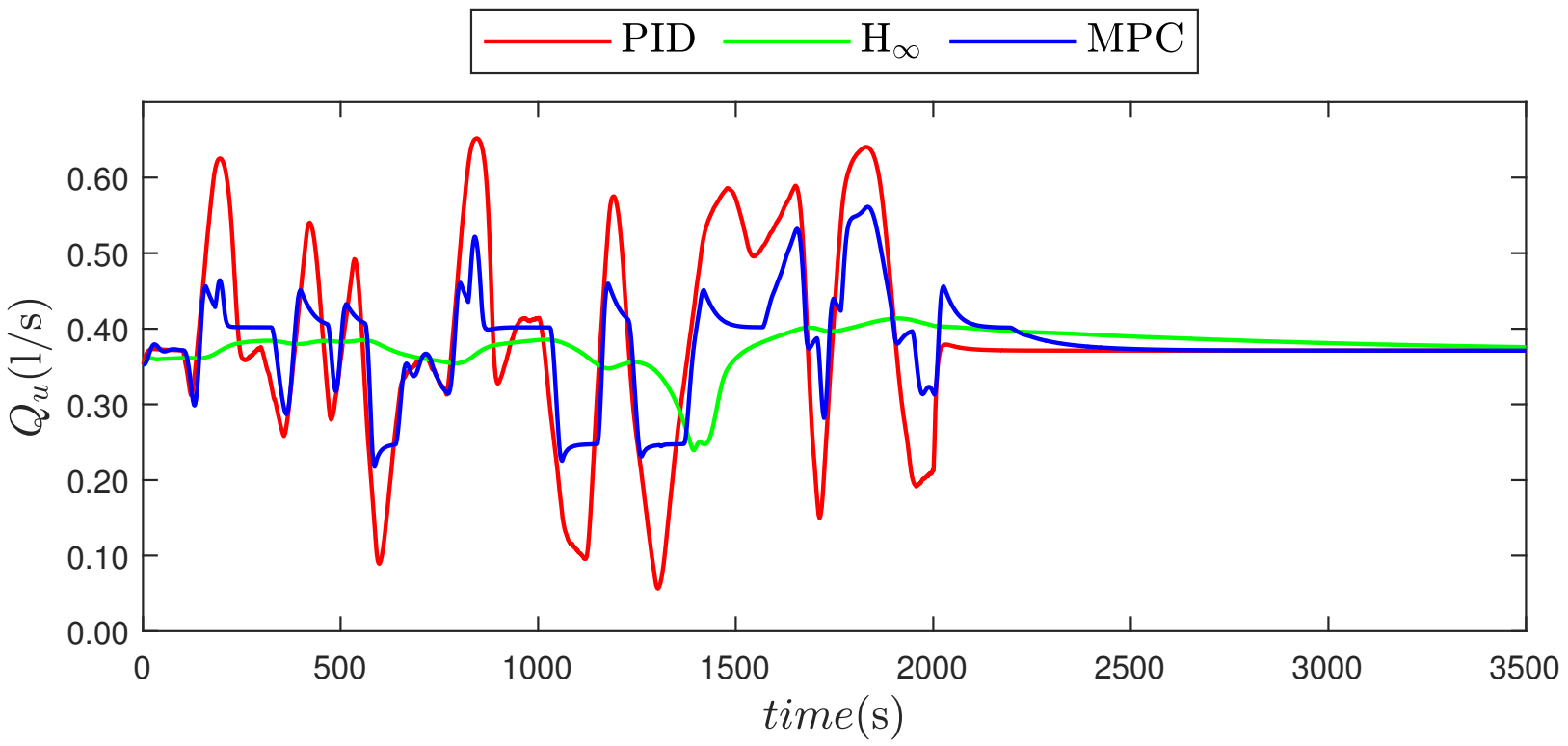

Figure 13. Hydrocyclone underflow liquid flow.
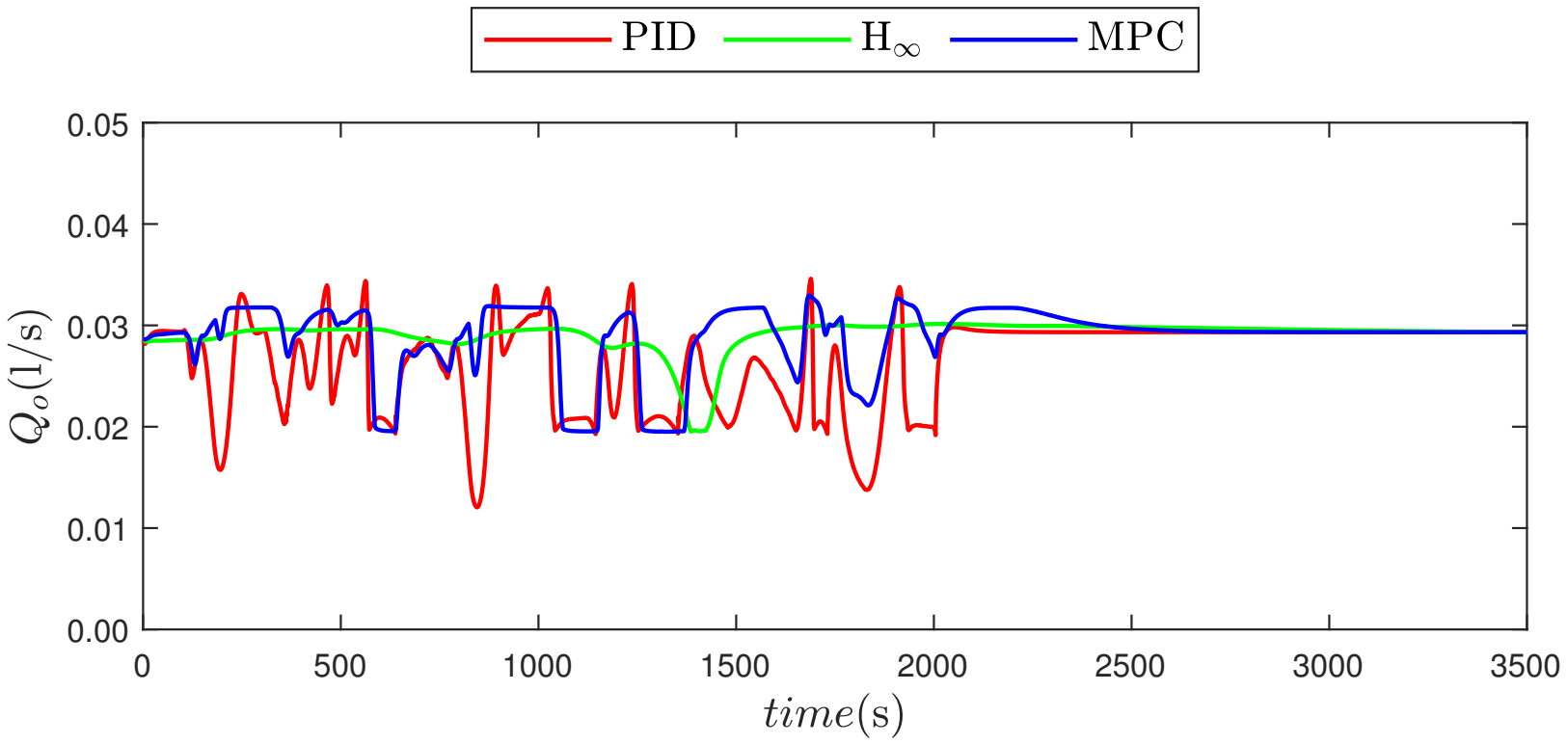

Figure 14. Hydrocyclone overflow liquid flow. 


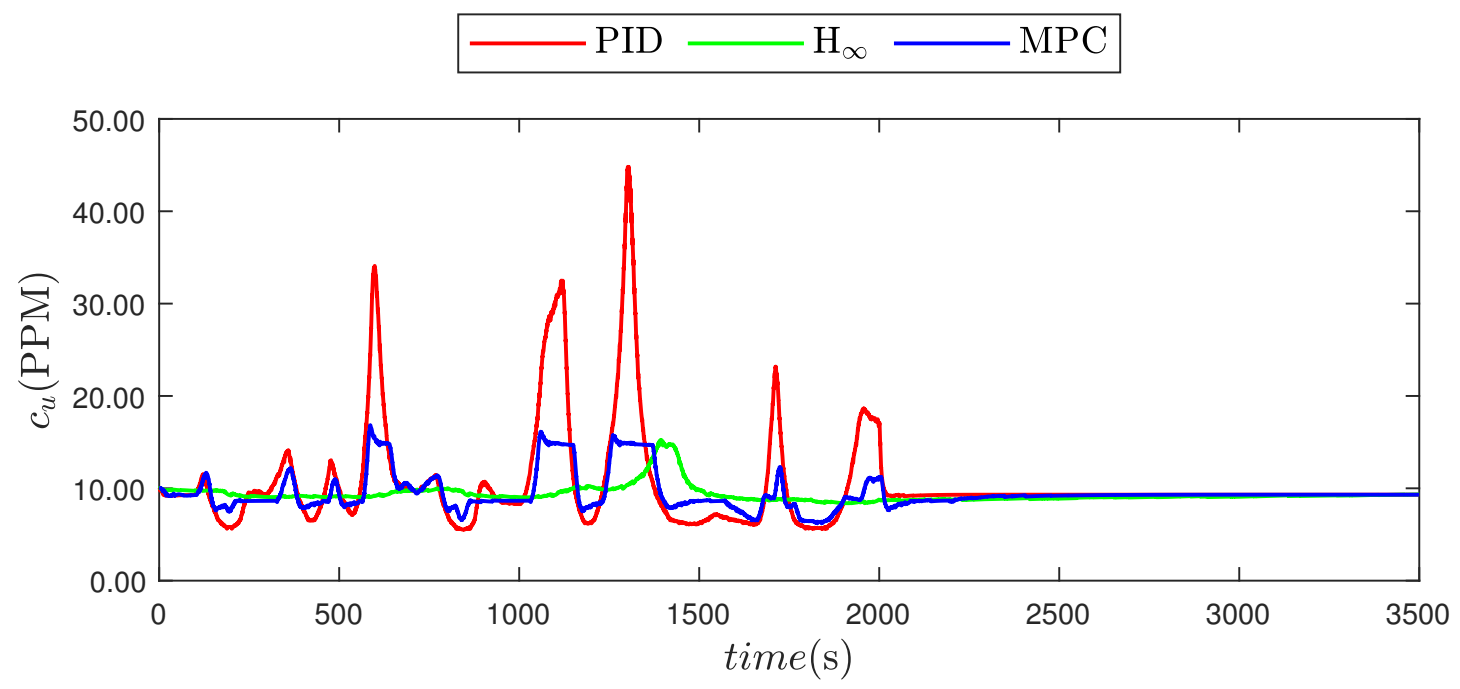

Figure 15. Hydrocyclone underflow concentration.

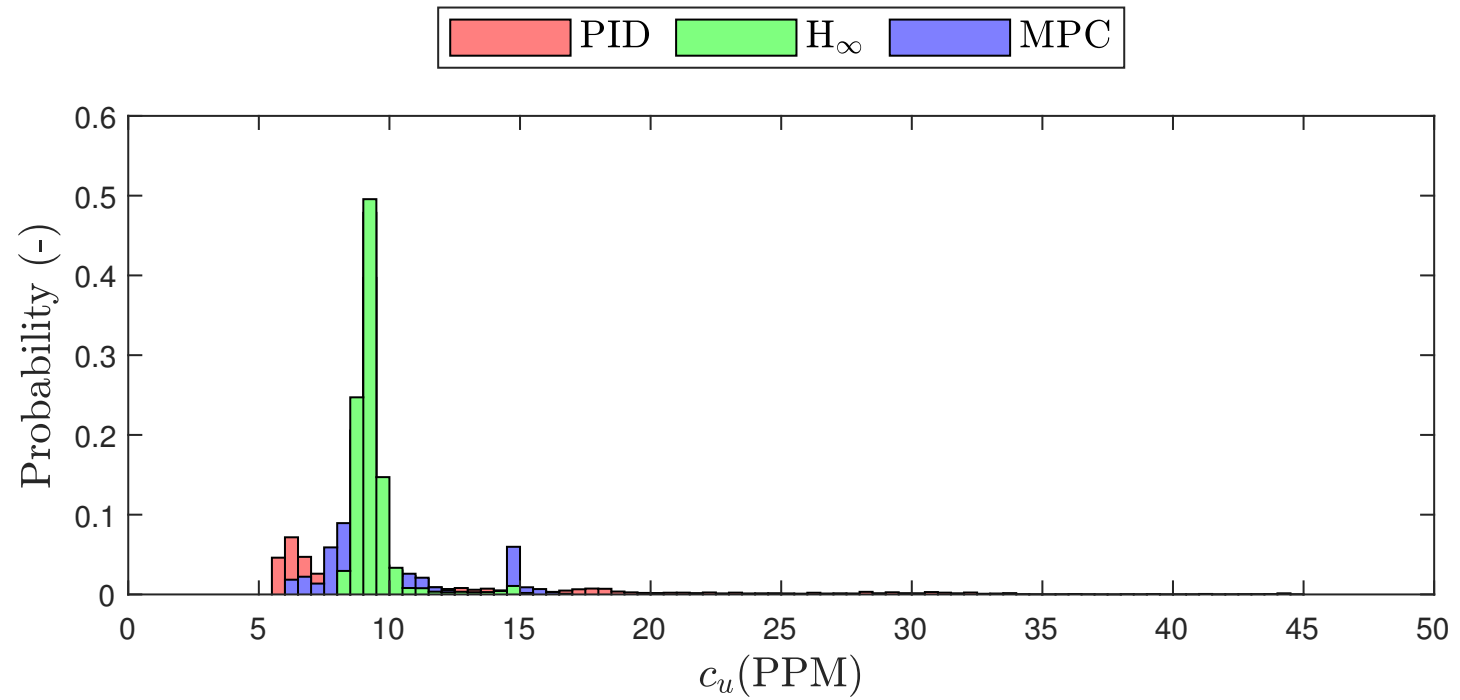

Figure 16. Histogram of the hydrocycone underflow concentration.

$\square$ PID $\square \mathrm{H}_{\infty} \square \mathrm{MPC}$

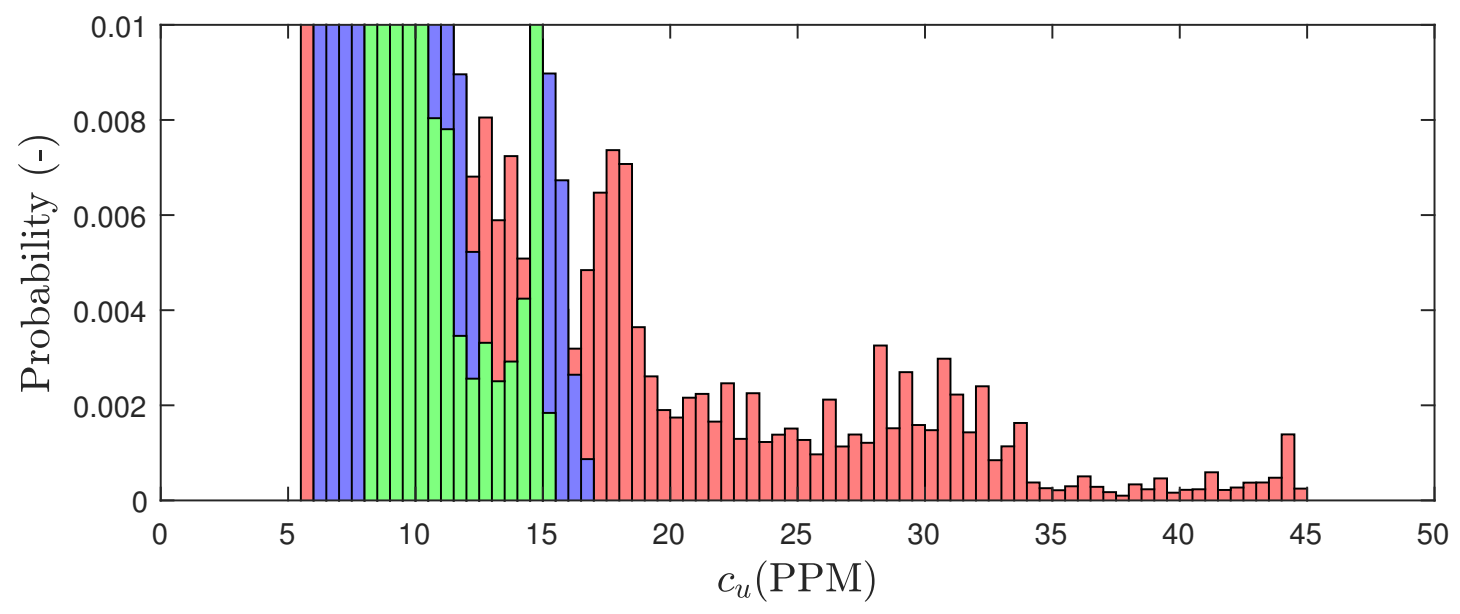

Figure 17. Histogram (zoom) of the hydrocyclone underflow concentration. 


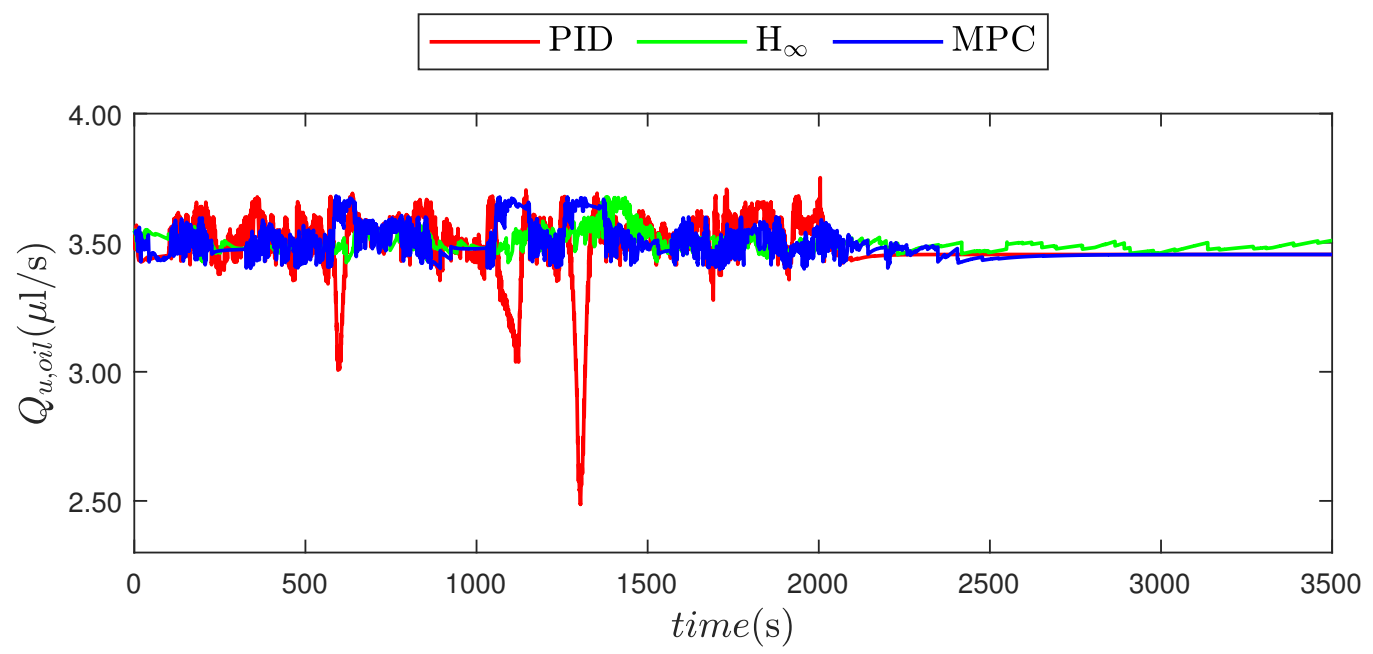

Figure 18. Hydrocyclone underflow oil flow.

As the simulation model does not account for the oil droplets' turbulence-induced random-walk, there exists a $d_{100}$ for both the separator and the hydrocyclone models. When an oil droplet has a diameter of $d_{100}$ or more, it is guaranteed to be separated. $d_{100}$ during the experiment for the separator and hydrocyclone are shown in Figures 19 and 20.

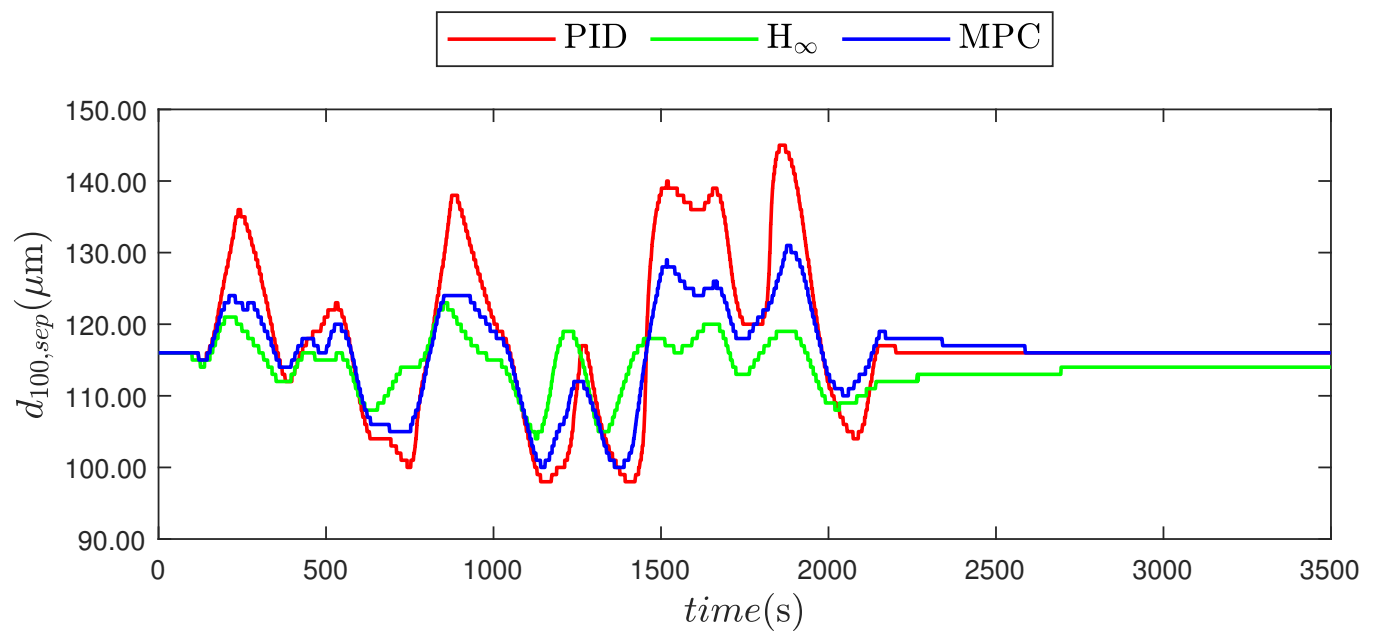

Figure 19. $d_{100}$ in separator water-phase outlet (hydrocycone inlet).

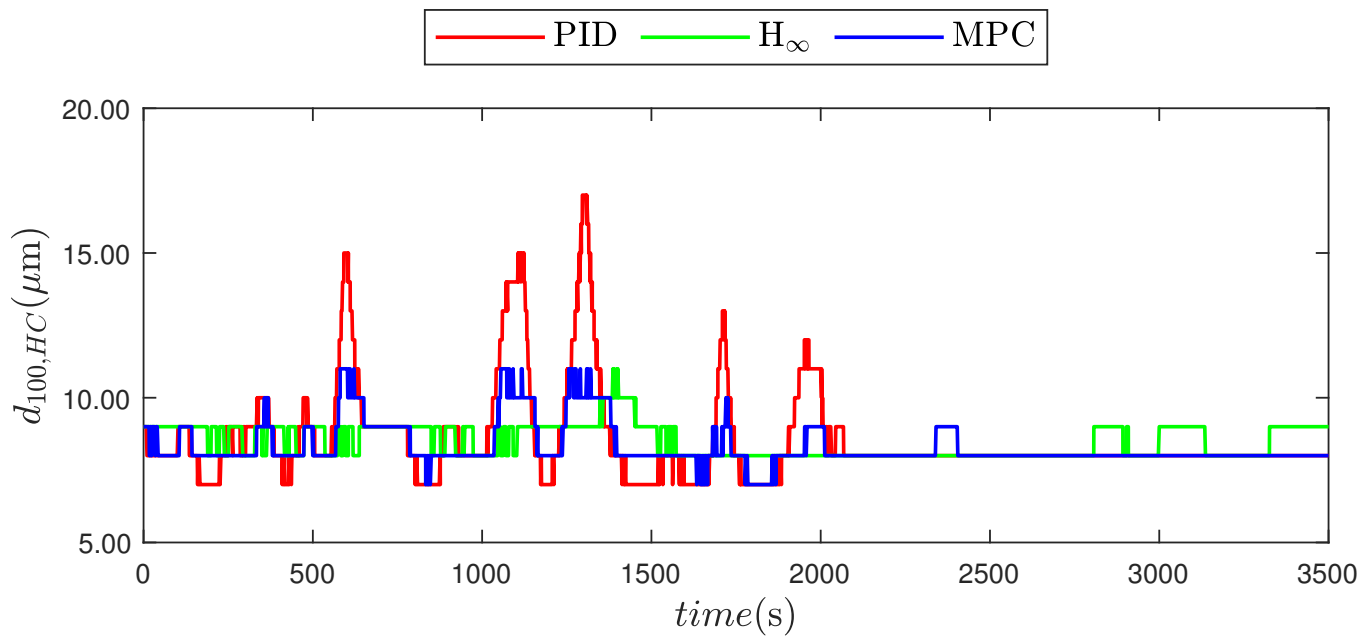

Figure 20. $d_{100}$ in hydrocyclone underflow. 
$d_{50}$ denotes a oil droplet diameter with a $50 \%$ chance of being separated. $d_{50}$ during the experiment for the separator and hydrocyclone are shown in Figures 21 and 22, respectively.

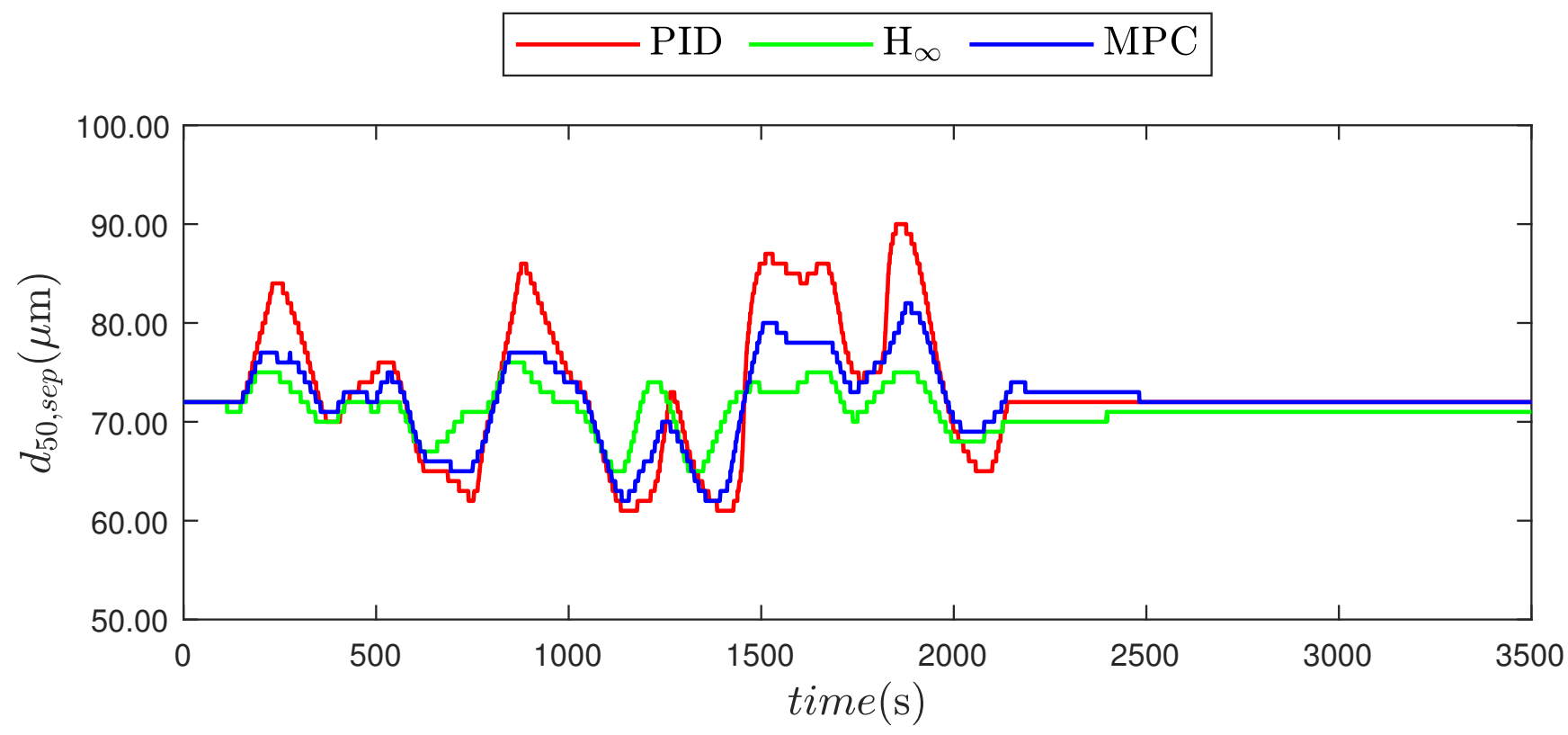

Figure 21. $d_{50}$ in separator water-phase outlet/hydrocyclone inlet.
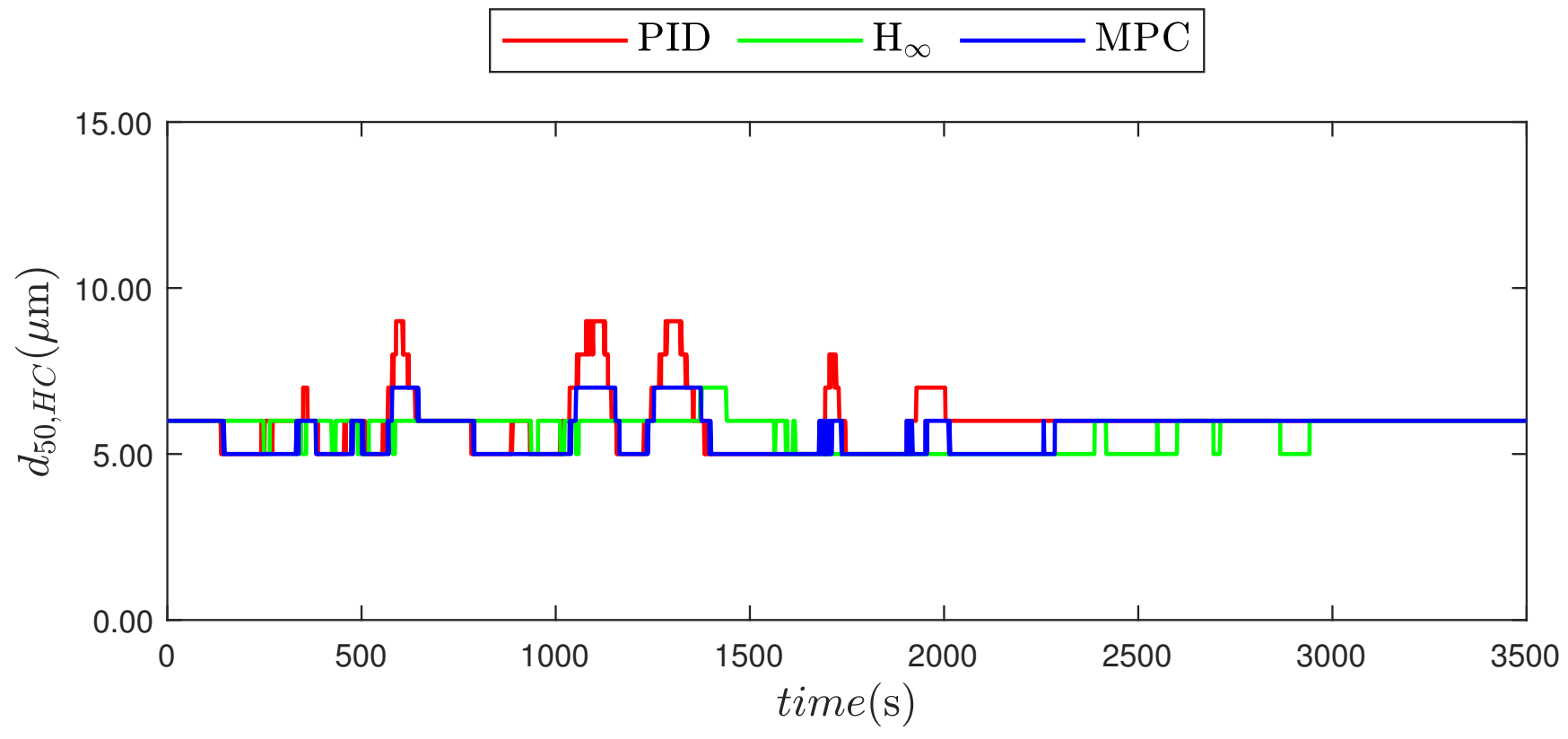

Figure 22. $d_{50}$ in hydrocyclone underflow.

The total accumulated flow, volume averages, and time sample averages are summarized in Table 1.

Interestingly, the PID control exhibits the lowest discharged volume concentration of oil, $c_{u}$, as shown in Table 1, but the results are very close to each other; i.e., the highest discharge concentration is only $1.7 \%$ higher. The largest variations in $c_{u}$ occur with the PID control, with a standard deviation of 5.3 PPM, whereas the standard deviation with the $H_{\infty}$ control and the MPC are $82 \%$ and $64 \%$ lower, respectively. Despite the PID control having the lowest discharged volume of oil, it has the largest maximum oil concentration of 44.8 PPM, whereas the $H_{\infty}$ control and the MPC are 15.2 PPM and 16.8 PPM, respectively. As expected, the PID solution has the most total valve travel as it aggressively maintains a 
nearly constant $h_{i}$. The MPC solution has a $V_{o}$ travel distance similar to the PID control's, which is attributed to prioritizing both PDR and $h_{i}$ in that order. However, the $H_{\infty}$ has much less valve travel due to its relaxation.

Table 1. Selected accumulated values and average concentrations of the $3500 \mathrm{~s}$ simulations.

\begin{tabular}{|c|c|c|c|c|c|}
\hline Total Accumulated & & Unit & PID & $\mathbf{H}_{\infty}$ & MPC \\
\hline Liquid flow separator inlet & & (L) & 1785.7 & 1785.7 & 1785.7 \\
\hline Liquid flow separator oil outlet & & (L) & 355.55 & 364.06 & 355.58 \\
\hline Liquid flow separator water outlet & & (L) & 1430.1 & 1421.6 & 1430.1 \\
\hline Oil flow separator water outlet & & (mL) & 1588.3 & 1497.4 & 1551.4 \\
\hline Liquid flow hydrocyclone overflow & & (L) & 93.071 & 101.85 & 101.06 \\
\hline Liquid flow hydrocyclone underflow & & (L) & 1337.1 & 1319.8 & 1329 \\
\hline Oil flow hydrocyclone underflow & & (mL) & 12.190 & 12.241 & 12.215 \\
\hline Underflow valve travel distance & & $(-)$ & 7.5994 & 0.42053 & 3.6072 \\
\hline Overflow valve travel distance & & $(-)$ & 16.143 & 1.4416 & 15.147 \\
\hline \multicolumn{6}{|l|}{ Volume Average } \\
\hline Oil concentration separator wa & & (PPM) & 1110.6 & 1053.3 & 1084.9 \\
\hline Oil concentration hydrocyclone underflow & & $(\mathrm{PPM})$ & 9.1174 & 9.2755 & 9.191 \\
\hline \multicolumn{6}{|l|}{ Time Sample Average } \\
\hline \multirow{3}{*}{ Oil concentration separator water outlet } & mean & (PPM) & 1095.9 & 1052.8 & 1077.9 \\
\hline & std & (PPM) & 131.1 & 43.874 & 79.064 \\
\hline & $\max$ & (PPM) & 1454 & 1162.7 & 1273.2 \\
\hline \multirow{3}{*}{ Oil concentration hydrocyclone underflow } & mean & (PPM) & 10.426 & 9.3391 & 9.4758 \\
\hline & std & (PPM) & 5.2978 & 0.93424 & 1.9029 \\
\hline & $\max$ & (PPM) & 44.814 & 15.206 & 16.823 \\
\hline
\end{tabular}

\section{Discussion}

The model used for this work's simulations is based on first principles and extended with simple data-driven modules in domains where first principles are no longer feasible. This is to achieve a grey-box model that is accurate and executable on the pilot plant. This implicates that parts of the model are simplified, from where deviations with the physical system might arise.

Some effects are not included in the model, namely:

- Oil droplet breakup and coalescence, which are expected to decrease the separation performance at high flow rates, as increased shear force increases droplet breakup.

- $\quad$ Turbulence induced random walk, which causes the grade efficiency curve to asymptotically approach $100 \%$ rather than approaching $100 \%$ quadratically, as a function of droplet size.

- Dynamic flow fields, which attributes setting time for the flow fields rather than instantaneously occurring. This effect is expected to decrease the performance of the hydrocyclone as it is known for performing poorly during transient and varying input flow conditions [41].

The separator model has undergone changes that affect the results. The calculation of superficial velocity from the outlet flow rate makes the model less reliant on a good value for the initial separation parameters, but the control solutions can more directly affect the residence time. The use of historical horizontal travel distances rather than assuming a steady state to calculate residence time reduces the control solutions control over the residence time and increases the precision of the model at the cost of computation time, but as the separator model is not yet validated, the exact increase of precision is hard to comment on. 


\section{Controller Performance}

The offshore PWT system is an interconnected and interdependent process system rendering the selection of control systems dependent on several factors. One of the most dominant reasons for the widespread offshore deployment of PID control is simplicity, which renders fault analysis easier, i.e., PID controllers are much more transparent than $\mathrm{H}_{\infty}$ control and MPC.

The steady-state value of $t_{r}$ is monotonically decreasing as a function of $Q_{s, w o}$ and monotonically increasing as a function of $h_{i}$. The PID controller's emphasis on keeping a near constant $h_{i}$ results in $t_{r}$ being dominated by $Q_{s, w o}$ and $Q_{s, w o}$ being approximately equal to $Q_{s} \cdot \alpha$. As the $\mathrm{H}_{\infty}$ controller keeps a near constant $Q_{s, w o}, t_{r}$ is dominated by $h_{i}$ instead, and $\dot{h}_{i}$ is approximately proportional to $\left(Q_{s}-\right.$ mean $\left.\left(Q_{s}\right)\right)$. The MPC solution serves as a midpoint between these two approaches, letting both $Q_{s, w o}$ and $h_{i}$ vary, and ends up with a closer to constant $t_{r}$, as it prioritizes PDR as long as it does not predict that the level constraints are reached if the current $Q_{s}$ were constant in the next $120 \mathrm{~s}$. As $c_{S}$ is monotonically decreasing as a function of $t_{r}$ and monotonically increasing as a function of $h_{i}$ it is almost entirely dependent on $Q_{s, w o}$ (or approximately $Q_{s} \cdot \alpha$ ) in steady-state. In transient contexts, $Q_{s, w o}$ is still very important for $c_{s}$, and the main difference in the control solutions is that the PID solution lack the dynamic delay from $\dot{h}_{i}$ to $h_{i}$.

The PID solution discharges the least amount of oil during the simulations. This is attributed to the three downward spikes in $Q_{u, o i l}$ seen in Figure 18 which is concurrent with the high spikes in $c_{u}$ and low values in $Q_{u}$ and $c_{s}$, which is seen in Figures 12, 13 and 15. The simulation with the MPC solution has similar transients with lower amplitude for $c_{S}$, $c_{u}$, and $Q_{u}$, but concurrent upward spikes in $Q_{u, o i l}$. This could indicate that $Q_{u, o i l}$ has a local maximum near the MPC solution's operation conditions. This maximum could be primarily dependent on $Q_{u}$, which is normally seen as the most important parameter for hydrocyclone separation performance at PDR above 2, but there is also a large difference in PDR values (indicating vastly different flow split) at these transients.

As vortex disturbance is not included in the model, the hydrocyclone separation performance is likely overestimated during varying/transient operating conditions, which will affect the PID controller's performance the most.

Table 2 summarizes the relative performance metrics of the three simulated control systems. The PID-control solution excels in being simple and easy to diagnose. The $\mathrm{H}_{\infty}$ solution excels in being the most relaxed, leading to least valve wear, least propagation of the input flow rate disturbance, and least variation in discharge oil concentration. The MPC solution is much like a midpoint between the PID and $\mathrm{H}_{\infty}$ solutions but offers explicitly defined constraints on $H_{i}$, which enables the separator tanks to be used as a buffer, to reduce the propagation of the input disturbance. The relative large differences between the $\mathrm{H}_{\infty}$ and MPC solutions despite the similar design goals can be attributed to the conservative design of the input disturbance model in the MPC solution's augmented model; i.e., the augmented model assumes that the current observed inflow $Q_{l i}$ is the inflow in the entire prediction horizon. To bring the MPC solution's performance in line with the $\mathrm{H}_{\infty}$ solution's performance when $h_{i}$ is between the constrains, it needs an input disturbance model that better represents the input disturbance that can be achieved either by returning to the equilibrium point within the control horizon or by correctly predicting the oscillations of the input disturbance. MPC solutions that attempt the latter have, however, been tested previously and been found to perform poorly when they predict an incorrect oscillation. A different approach to get the benefits from both solutions could be to forgo the augmented model normally applied in MPC and use a method like $\mathrm{H}_{\infty}$ Loop-Shaped MPC instead [42]. 
Table 2. Summarizing the relative performance metrics.

\begin{tabular}{lccc}
\hline Metric & PID & H $_{\infty}$ & MPC \\
\hline Control system complexity & Low & Medium & High \\
Total oil discharge & Similar & Similar & Similar \\
Discharge concentration variation & High & Low & Medium \\
Valve wear & High & Low & Medium \\
Disturbance propagation & High & Low & Medium \\
Explicitly defined constraints & No & No & Yes \\
\hline
\end{tabular}

\section{Conclusions}

This work compared the deoiling performance of PID control, $\mathrm{H}_{\infty}$ control and MPC to control the combined PWT system, using the inter-phase level and PDR as control variables. Grey-box models of the separator and hydrocyclone were combined to enable estimations of performance metrics, such as oil concentration and oil droplet size distributions. This work further confirms, highlights, and quantifies previous claims related to the expected performance of the controllers, specifically, that the PID control will maintain the interface level at the set-point, but propagate the variations of the input disturbance, and that the MPC can maintain the interface level within its predefined upper and lower constraints. From simulations, the highlighted results are as follows:

- The PID solution has the highest total valve distance traveled, which causes the most wear to the underflow and overflow valve.

- $\mathrm{H}_{\infty}$ has the least total valve distance traveled.

- Both PID and MPC solutions can keep $h_{i}$ between the chosen constraints, while the $\mathrm{H}_{\infty}$ can not.

- Both MPC and $\mathrm{H}_{\infty}$ solutions can avoid extreme PDR values, with $\mathrm{H}_{\infty}$ keeping the most constant value.

- $\quad$ PID control has the lowest mean $c_{u}$ (volumetric) but also the highest variance, resulting in the highest maximum concentration.

- Measured in mean $c_{u}$ (volumetric) the three solutions performs very similarly.

- Most of the performance metrics of MPC are between those of the PID and $\mathrm{H}_{\infty}$ control.

- $\quad \mathrm{MPC}$ is able to assign priority to manipulate interface level if a constraint is reached within the current sample's prediction horizon.

With the successful MPC results of satisfying constraints while utilizing the grey-box model structure, promising future work consists of reevaluating the operational philosophy. Specifically, applying weights and constraints to the individual operational performance metrics for the control to optimize. A better understanding of the input disturbance should give better results not only through a more precise input disturbance model, but also as an aid to design the operational philosophy. Being able to run PWT with different operational strategies can add much more value than simply satisfying interface-level constraints and maintaining PDR. To take full advantage of the combined model, experimental validation of the separator model should be performed in future works.

Author Contributions: Conceptualization, methodology, investigation, simulations, analysis, and writing by L.H., M.V.B., S.P. and Z.Y. All authors have read and agreed to the published version of the manuscript.

Funding: This research was funded by the DHRTC and AAU joint project: "Big data method for identifying cause and effect of downtime" (AAU Proj-no.: 222984).

Data Availability Statement: The data presented in this study are available on request from the corresponding author.

Acknowledgments: The authors thank the support from the DTU-DHRTC. Thanks also go to AAU colleagues: S. Jespersen, D. S. Hansen, and P. Durdevic for many valuable discussions and technical support. 
Conflicts of Interest: The authors declare no conflict of interest.

\section{Nomenclature}

$\alpha \quad$ Separator water cut in liquid inflow

$\beta_{2} \quad$ Hydrocyclone cone angle

$\Delta \rho \quad$ Density difference between water and oil

$\triangle P \quad$ Pressure difference

$\Delta P_{V o} \quad$ Pressure difference over the overflow valve

$\Delta P_{V u} \quad$ Pressure difference over the underflow valve

$\delta_{u} \quad$ Oil distribution vector at hydrocyclone underflow

$\delta_{\log } \quad$ Approximated probability mass function of $\Phi_{\text {in }}$

$\delta_{w i} \quad$ Oil distribution vector at separator water phase inlet

$\delta_{w o} \quad$ Oil distribution vector at separator water outlet

$\gamma \quad$ Separator liquid flow split

$\mu \quad$ Dynamic viscosity of water

$\Phi_{i n} \quad$ Continues oil distribution at separator water phase inlet

$\varphi_{\text {oiw }} \quad$ Separator initial OiW ratio

$\varphi_{\text {wio }} \quad$ Separator initial $\mathrm{WiO}$ ratio

$\psi \quad$ Vector of droplet volumes

$\theta_{i} \quad$ Coefficients for $Y, i \in\{1,2,3,4\}$

$\zeta_{\text {oiw }} \quad$ Separator final OiW ratio

$\zeta_{\text {wio }} \quad$ Separator final WiO ratio

$A(x) \quad$ Function for the cross-section area of the separator below the height $x$

$A_{l} \quad$ Linear model state matrix

$B_{d} \quad$ Linear model disturbance input matrix

$B_{l} \quad$ Linear model control input matrix

$C_{1} \quad$ Hydrocyclone inlet speed imperfection coefficient

$C_{2} \quad$ Hydrocyclone tangential speed dropoff coefficient

$C_{l} \quad$ Linear model output matrix

$c_{\max } \quad$ Upper output constraint for the MPC solution

$c_{\min } \quad$ Lower output constraint for the MPC solution

$c_{u} \quad$ OiW concentration in hydrocyclone underflow

$c_{w o} \quad$ OiW concentration in separator water outlet

d Vector of droplet sizes

$d_{100, H C}$ Oil droplet diameter with $100 \%$ chance of being separated in the hydrocyclone

$d_{100 \text {,sep }} \quad$ Oil droplet diameter with $100 \%$ chance of being separated in the separator

$d_{50, H C} \quad$ Oil droplet diameter with $50 \%$ chance of being separated in the hydrocyclone

$d_{50 \text {,sep }} \quad$ Oil droplet diameter with $50 \%$ chance of being separated in the separator

$D_{i} \quad$ Characteristic hydrocyclone diameters, $i \in\{n, u\}$

$d_{\text {max }} \quad$ Upper input constraint for the MPC solution

$d_{\text {min }} \quad$ Lower input constraint for the MPC solution

$E_{h i} \quad$ Tracking error for $h_{i}$ control

$E_{P D R} \quad$ Tracking error for PDR control

$F_{h}(\cdot) \quad$ Hammerstein function for the MPC solution

$F_{S} \quad$ Hydrocyclone flow split

$g \quad$ Gravitational acceleration

$h_{i} \quad$ Separator liquid interface level

$h_{l} \quad$ Separator total liquid level

$h_{o d} \quad$ Vertical traveled distance in the separator for each droplet size

$J(\cdot) \quad$ Cost function for the MPC solution

$K \quad$ Flow conductance parameter

$K_{H} \quad$ Dynamic controller for the $\mathrm{H}_{\infty}$ solution

$K_{V o} \quad$ Overflow valve flow conductance parameter 
$K_{V u} \quad$ Underflow valve flow conductance parameter

$L_{i} \quad$ Hydrocyclone segment axial lengths, $i \in\{3,4\}$

$M_{G} \quad$ Molar mass of the gas phase

$N \quad$ Possible solutions for $v_{S}$

$n \quad$ Hydrocyclone forced/frex coefficient

$N_{t r} \quad$ Separator residence time in terms of number of samples

$P_{H} \quad$ Augmented plant model for the $\mathrm{H}_{\infty}$ solution

$P_{S} \quad$ Separator gas pressure

$P D R \quad$ Hydrocyclone pressure drop ration

$Q \quad$ Flow rate

$Q_{g i} \quad$ Separator gas inflow rate

$Q_{g o} \quad$ Separator gas outflow rate

$Q_{l i} \quad$ Separator liquid inflow rate

$Q_{o o} \quad$ Separator oil outlet liquid flow rate

$Q_{0} \quad$ Hydrocyclone overflow liquid flow rate

$Q_{u, \text { oil }} \quad$ Hydrocyclone underflow oil flow rate

$Q_{u} \quad$ Hydrocyclone underflow liquid flow rate

$Q_{w o} \quad$ Separator water outlet liquid flow rate

$Q_{w p} \quad$ Separator water phase liquid flow rate

$R \quad$ Gas constant

$(r, z) \quad$ Radial and axial coordinates inside the hydrocyclone

$R_{d} \quad$ Vector of all radial starting position of all critical oil droplet trajectories inside the hydrocyclone

$r_{h i} \quad$ Set-point for $h_{i}$ control

$R_{L} \quad$ Radius of locus of zero axial velocity inside the hydrocyclone

$r_{P D R} \quad$ Set-point for PDR control

$R_{R} \quad$ Recirculation rate

$r_{u} \quad$ The ratio of droplets remaining in the underflow

$r_{w o} \quad$ The ratio of droplets remaining in the separator water outlet

$R_{z}(z) \quad$ Inner hydocyclone wall radius as function of $z$

$s_{t} \quad$ Combined model sampling time

$T \quad$ Process temperature

$T_{\mathcal{C}} \quad$ Hydrocyclone dispersed phase tangential velocity field

$t_{r} \quad$ Separator residence time

$u_{\Delta} \quad$ Incremental control inputs for the MPC solution

$U_{d} \quad$ Hydrocyclone dispersed phase radial velocity field

$u_{H} \quad$ Controllable inputs for the $\mathrm{H}_{\infty}$ solution

$u_{r} \quad$ Controllable inputs for the MPC solution

$u_{u m} \quad$ Unknown disturbance input for the MPC solution

$U_{V o} \quad$ Overflow valve actuator set-point

$U_{V u} \quad$ Underflow valve actuator set-point

$V \quad$ Output weight matrix for the MPC solution

$V_{o} \quad$ Overflow valve position

$v_{S} \quad$ Superficial velocity through separator the water phase

$V_{T} \quad$ Terminal output weight matrix for the MPC solution

$V_{u} \quad$ Underflow valve position

$W \quad$ Input weight matrix for the MPC solution

$W_{c} \quad$ Hydrocyclone dispersed phase axial velocity field

$w_{H} \quad$ Unknown disturbance input for the $\mathrm{H}_{\infty}$ solution

$\hat{x}_{0} \quad$ Estimated states for the MPC solution

$Y \quad$ Hydrocyclone axial velocity profile

$y_{H} \quad$ Measured outputs for the $\mathrm{H}_{\infty}$ solution

$y_{r} \quad$ Predicted outputs for the MPC solution

$z_{H} \quad$ Controlled outputs for the $\mathrm{H}_{\infty}$ solution 


\section{References}

1. Hansen, D. Online Monitoring and Analysis of Water Quality in Offshore Oil \& Gas Production. Ph.D. Thesis, Aalborg Universitetsforlag, Aalborg, Denmark, 2020. [CrossRef]

2. Administration, U.E.I. International Energy Outlook 2019. 2019. Available online: https://www.eia.gov/ (accessed on 19 December 2021).

3. Choi, M. Hydrocyclone Produced Water Treatment for Offshore Developments. In SPE Annual Technical Conference and Exhibition Society of Petroleum Engineers: New Orleans, LA, USA, 1990; pp. 473-480. [CrossRef]

4. Amini, S.; Mowla, D.; Golkar, M.; Esmaeilzadeh, F. Mathematical modelling of a hydrocyclone for the down-hole oil-water separation (DOWS). Chem. Eng. Res. Des. 2012, 90, 2186-2195. [CrossRef]

5. Produced Water Treatment: Yesterday, Today, and Tomorrow. Oil Gas Facil. 2012, 1. Available online: https://jpt.spe.org/ produced-water-treatment-yesterday-today-and-tomorrow (accessed on 5 November 2021).

6. Yang, Z.; Pedersen, S.; Løhndorf, P. Cleaning the Produced Water in Offshore Oil Production by Using Plant-wide Optimal Control Strategy. In Proceedings of the OCEANS'14 MTS/IEEE Conference, St. John's, NL, Canada, 14-19 September 2014; [CrossRef]

7. Yang, Z.; Pedersen, S.; Løhndorf, P.; Mai, C.; Hansen, L.; Jepsen, K.; Aillos, A.; Andreasen, A. Plant-wide Control Strategy for Improving Produced Water Treatment. In Proceedings of the 2016 International Field Exploration and Development Conference (IFEDC), Beijing, China, 11-12 August 2016. [CrossRef]

8. Fakhru'l-Razi, A.; Pendashteh, A.; Abdullah, L.C.; Biak, D.R.A.; Madaeni, S.S.; Abidin, Z.Z. Review of technologies for oil and gas produced water treatment. J. Hazard. Mater. 2009, 170, 530-551. [CrossRef]

9. OSPAR Commission. North Sea Manual on Maritime Oil Pollution Offences; Technical Report; OSPAR Commission: London, UK, 2010.

10. Danish Environmental Protection Agency. Generel Tilladelse for Mærsk Olie og Gas A/S (Mærsk Olie) til Anvendelse, Udledning og Anden Bortskaffelse af Stoffer og Materialer, Herunder Olie og Kemikalier i Produktions- og Injektionsvand fra Produktionsenhederne Halfdan, Dan, Tyra og Gorm for Perio; Technical Report; Danish Environmental Protection Agency: Copenhagen, Denmark, 2016.

11. Brette, F.; Machado, B.; Cros, C.; Incardona, J.P.; Scholz, N.L.; Block, B.A. Crude oil impairs cardiac excitation-contraction coupling in fish. Science 2014, 343, 772-776. [CrossRef]

12. Ekins, P.; Vanner, R.; Firebrace, J. Zero emissions of oil in water from offshore oil and gas installations: Economic and environmental implications. J. Clean. Prod. 2007, 15, 1302-1315. [CrossRef]

13. Bakke, T.; Klungsøyr, J.; Sanni, S. Environmental impacts of produced water and drilling waste discharges from the Norwegian offshore petroleum industry. Mar. Environ. Res. 2013, 92, 154-169. [CrossRef]

14. Hasselberg, L.; Meier, S.; Svardal, A. Effects of alkylphenols on redox status in first spawning Atlantic cod (Gadus morhua). Aquat. Toxicol. 2004, 69, 95-105. [CrossRef]

15. Hylland, K. Polycyclic Aromatic Hydrocarbon (PAH) Ecotoxicology in Marine Ecosystems. J. Toxicol. Environ. Health Part A 2007, 69, 109-123. [CrossRef] [PubMed]

16. Thomas, K.V.; Langford, K.; Petersen, K.; Smith, A.J.; Tollefsen, K.E. Effect-Directed Identification of Naphthenic Acids as Important in Vitro Xeno-Estrogens and Anti-Androgens in North Sea Offshore Produced Water Discharges. Environ. Sci. Technol. 2009, 43, 8066-8071. [CrossRef] [PubMed]

17. Yang, M. Measurement of Oil in Produced Water. In Produced Water, 1st ed.; Lee, K., Neff, J.M., Eds.; Springer: New York, NY, USA, 2011; Chapter 2, pp. 57-88. [CrossRef]

18. Toril Inga, R.; Garpestad, E.; Tangvald, M.; Frost, T. Results and Commitments from the Zero Discharge Work on Produced Water Discharges on the Norwegian Continental Shelf. In Proceedings of SPE International Conference on Health, Safety, and Environment in Oil and Gas Exploration and Production; Society of Petroleum Engineers: Calgary, AB, Canada, 2004; pp. 1327-1332. [CrossRef]

19. Bram, M.V. Greybox Modeling and Validation of Deoiling Hydrocyclones. Ph.D. Thesis, Aalborg Universitetsforlag, Aalborg, Denmark, 2020.

20. Husveg, T.; Johansen, O.; Bilstad, T. Operational control of hydrocyclones during variable produced water flow rates-Frøy case study. SPE Prod. Oper. 2007, 22, 294-300. [CrossRef]

21. Løhndorf, P.; Pedersen, S.; Yang, Z. Challenges in Modelling and Control of Offshore De-oiling Hydrocyclone Systems. In Proceedings of the 13th European Workshop on Advanced Control \& Diagnosis , ACD'16, Lille, France, 17-18 November 2016; IOP Publishing: Bristol, UK, 2017; Volume 783. [CrossRef]

22. Bram, M.V.; Hassan, A.A.; Hansen, D.S.; Durdevic, P.; Pedersen, S.; Yang, Z. Experimental modeling of a deoiling hydrocyclone system. In Proceedings of the 2015 20th International Conference on Methods and Models in Automation and Robotics (MMAR), Miedzyzdroje, Poland, 24-27 August 2015; pp. 1080-1085.

23. Mokhatab, S.; Towler, B.F. Severe Slugging in Flexible Risers: Review of Experimental Investigations and OLGA Predictions. Pet. Sci. Technol. 2007, 25, 867-880. [CrossRef]

24. Pedersen, S.; Durdevic, P.; Yang, Z. Challenges in slug modeling and control for offshore oil and gas productions: A review study. Int. J. Multiph. Flow 2017, 88, 270-284. [CrossRef]

25. Mokhatab, S. Severe Slugging in Offshore Production Systems; Nova Science Publishers: Hauppauge, NY, USA, 2010.

26. Pedersen, S.; Løhndorf, P.; Yang, Z. Influence of riser-induced slugs on the downstream separation processes. J. Pet. Sci. Eng. 2017, 154, 337-343. [CrossRef] 
27. Pedersen, S. Plant-Wide Anti-Slug Control for Offshore Oil and Gas Processes. Ph.D. Thesis, Aalborg Universitetsforlag, Aalborg, Denmark, 2016. [CrossRef]

28. Durdevic, P.; Yang, Z. Application of $\mathrm{H}_{\infty}$ Robust Control on a Scaled Offshore Oil and Gas De-oiling Facility. Energies 2018, 11, 287. [CrossRef]

29. Hansen, L.; Durdevic, P.; Jepsen, K.L.; Yang, Z. Plant-wide Optimal Control of an Offshore De-oiling Process Using MPC Technique. IFAC-PapersOnLine 2018, 51, 144-150. [CrossRef]

30. Das, T.; Heggheim, S.J.; Dudek, M.; Verheyleweghen, A.; Jäschke, J. Optimal Operation of a Subsea Separation System Including a Coalescence Based Gravity Separator Model and a Produced Water Treatment Section. Ind. Eng. Chem. Res. 2019, 58, 4168-4185. [CrossRef]

31. Hansen, L.; Jepsen, K.L.; Durdevic, P.; Yang, Z. Comparison of Inlet Observers for a De-Oiling Gravity Separator. In 15th European Workshop on Advanced Control and Diagnosis (ACD 2019); Springer International Publishing AG: Basel, Switzerland, 2022. [CrossRef]

32. Bram, M.V.; Jespersen, S.; Hansen, D.S.; Yang, Z. Control-Oriented Modeling and Experimental Validation of a Deoiling Hydrocyclone System. Processes 2020, 8, 1010. [CrossRef]

33. Pedersen, S.; Bram, M.V. The Impact of Riser-Induced Slugs on the Downstream Deoiling Efficiency. J. Mar. Sci. Eng. 2021, 9, 391. [CrossRef]

34. Bram, M.V.; Hansen, L.; Hansen, D.S.; Yang, Z. Grey-Box modeling of an offshore deoiling hydrocyclone system. In Proceedings of the 2017 IEEE Conference on Control Technology and Applications (CCTA), Maui, HI, USA, 27-30 August 2017; IEEE: Manhattan, NY, USA, 2017; pp. 94-98. [CrossRef]

35. Wolbert, D.; Ma, B.F.; Aurelle, Y.; Seureau, J. Efficiency estimation of liquid-liquid Hydrocyclones using trajectory analysis. AIChE J. 1995, 41, 1395-1402. [CrossRef]

36. Bram, M.V.; Hansen, L.; Hansen, D.S.; Yang, Z. Hydrocyclone Separation Efficiency Modeled by Flow Resistances and Droplet Trajectories. IFAC-PapersOnLine 2018, 51, 132-137. [CrossRef]

37. Bram, M.V.; Hansen, L.; Hansen, D.S.; Yang, Z. Extended Grey-Box Modeling of Real-Time Hydrocyclone Separation Efficiency. In Proceedings of the 2019 18th European Control Conference (ECC), Naples, Italy, 25-28 June 2019; IEEE: Manhattan, NY, USA, 2019; pp. 3625-3631. [CrossRef]

38. The Danish Energy Agency. Yearly Production, Injection, Flare, Fuel and Export in Si Units 1972-2017; The Danish Energy Agency: Copenhagen, Denmark, 2018.

39. Thew, M. Hydrocyclone Redesign for Liquid-Liquid Separation. Chem. Eng. 1986, 427, 17-23.

40. Meldrum, N. Hydrocyclones: A Solutlon to Produced-Water Treatment. SPE Prod. Eng. 1988, 3, 669-676. [CrossRef]

41. Husveg, T.; Rambeau, O.; Drengstig, T.; Bilstad, T. Performance of a deoiling hydrocyclone during variable flow rates. Miner. Eng. 2007, 20, 368-379. [CrossRef]

42. Bortoff, S.A.; Schwerdtner, P.; Danielson, C.; Di Cairano, S. H-Infinity Loop-Shaped Model Predictive Control with Heat Pump Application. In Proceedings of the 2019 18th European Control Conference (ECC), Naples, Italy, 25-28 June 2019; IEEE: Manhattan, NY, USA, 2019; pp. 2386-2393. [CrossRef] 